See discussions, stats, and author profiles for this publication at: https://www.researchgate.net/publication/326257025

\title{
Targeting mTORs by omega-3 fatty acids: A possible novel therapeutic strategy for neurodegeneration?
}

Article in Pharmacological Research · July 2018

DOI: 10.1016/j.phrs.2018.07.004

CITATIONS

8

12 authors, including:

A.) Ahmad reza Dehpour

(4) Tehran University of Medical Sciences

811 PUBLICATIONS 10,474 CITATIONS

SEE PROFILE
READS

361

Tarun Belwal

Zhejiang University

66 PUBLICATIONS 397 CITATIONS

SEE PROFILE

Some of the authors of this publication are also working on these related projects:

Bioactive secondary metabolites from cameroonian medicinal plants View project

A study on the function of calcium-parathormone-vitamin D axis and the role of IL-6 in BDL cirrhotic rats and the effect of Naltrexone and L-NAME View project 


\section{Accepted Manuscript}

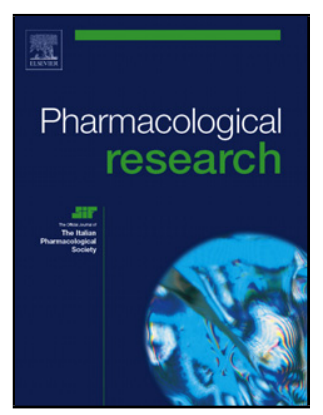

Title: Targeting mTORs by omega-3 fatty acids: a possible novel therapeutic strategy for neurodegeneration?

Authors: Samira Shirooie, Seyed Fazel Nabavi, Ahmad R. Dehpour, Tarun Belwal, Solomon Habtemariam, Sandro Argüelles, Antoni Sureda, Maria Daglia, Michał Tomczyk, Eduardo Sobarzo-Sanchez, Suowen Xu, Seyed Mohammad Nabavi

PII: S1043-6618(18)30531-0

DOI: https://doi.org/10.1016/j.phrs.2018.07.004

Reference: YPHRS 3941

To appear in: $\quad$ Pharmacological Research

Received date: $\quad 15-4-2018$

Revised date: $\quad 3-7-2018$

Accepted date: $\quad$ 5-7-2018

Please cite this article as: Shirooie S, Nabavi SF, Dehpour AR, Belwal T, Habtemariam S, Argüelles S, Sureda A, Daglia M, Tomczyk M, Sobarzo-Sanchez E, Xu S, Nabavi SM, Targeting mTORs by omega-3 fatty acids: a possible novel therapeutic strategy for neurodegeneration?, Pharmacological Research (2018), https://doi.org/10.1016/j.phrs.2018.07.004

This is a PDF file of an unedited manuscript that has been accepted for publication. As a service to our customers we are providing this early version of the manuscript. The manuscript will undergo copyediting, typesetting, and review of the resulting proof before it is published in its final form. Please note that during the production process errors may be discovered which could affect the content, and all legal disclaimers that apply to the journal pertain. 
Targeting mTORs by omega-3 fatty acids: a possible novel therapeutic strategy for neurodegeneration?

Samira Shirooie ${ }^{1}$, Seyed Fazel Nabavi ${ }^{2}$, Ahmad R. Dehpour ${ }^{3,}{ }^{4}$, Tarun Belwal ${ }^{5}$, Solomon Habtemariam $^{6}$, Sandro Argüelles ${ }^{7}$, Antoni Sureda ${ }^{8}$, Maria Daglia ${ }^{9}$, Michał Tomczyk ${ }^{10}$, Eduardo Sobarzo-Sanchez ${ }^{11,12}$, Suowen Xu ${ }^{13}$, Seyed Mohammad Nabavi ${ }^{2 *}$

1_ Department of Pharmacology, Faculty of Pharmacy, Kermanshah University of Medical Sciences, Kermanshah, Iran

2. Applied Biotechnology Research Center, Baqiyatallah University of Medical Sciences, Tehran 14359-16471, Iran

3- Department of Pharmacology, Faculty of Medicine, Tehran University of Medical Sciences, Tehran, Iran

4_ Experimental Medicine Research Center, Tehran University of Medical Sciences, Tehran, Iran

5- G.B. Pant National Institute of Himalayan Environment and Sustainable Development, Kosi Katarmal, Almora, Uttarakhand, India

6_ Pharmacognosy Research Laboratories \& Herbal Analysis Services UK, University of Greenwich, Chatham-Maritime, Kent ME4 4TB, UK

7_ Department of Physiology, Faculty of Pharmacy, University of Seville, Seville, Spain

8_ Research Group on Community Nutrition and Oxidative Stress (NUCOX) and CIBEROBN (Physiopathology of Obesity and Nutrition CB12/03/30038), University of Balearic Islands, Palma de Mallorca E-07122, Balearic Islands, Spain 
9_ Department of Drug Sciences, Medicinal Chemistry and Pharmaceutical Technology

Section, University of Pavia, Italy

10_ Department of Pharmacognosy, Faculty of Pharmacy, Medical University of Białystok, ul.

Mickiewicza 2a, 15-230, Białystok, Poland

11- Laboratory of Pharmaceutical Chemistry, Faculty of Pharmacy, University of Santiago de

Compostela 15782, Spain

12- Instituto de Investigación en Innovación en Salud, Facultad de Ciencias de la Salud,

Universidad Central de Chile, Santiago, Chile

13. Aab Cardiovascular Research Institute, University of Rochester, Rochester, NY, 14623

*Corresponding to: SM Nabavi, Nabavi208@gmail.com

\section{Graphical abstract}

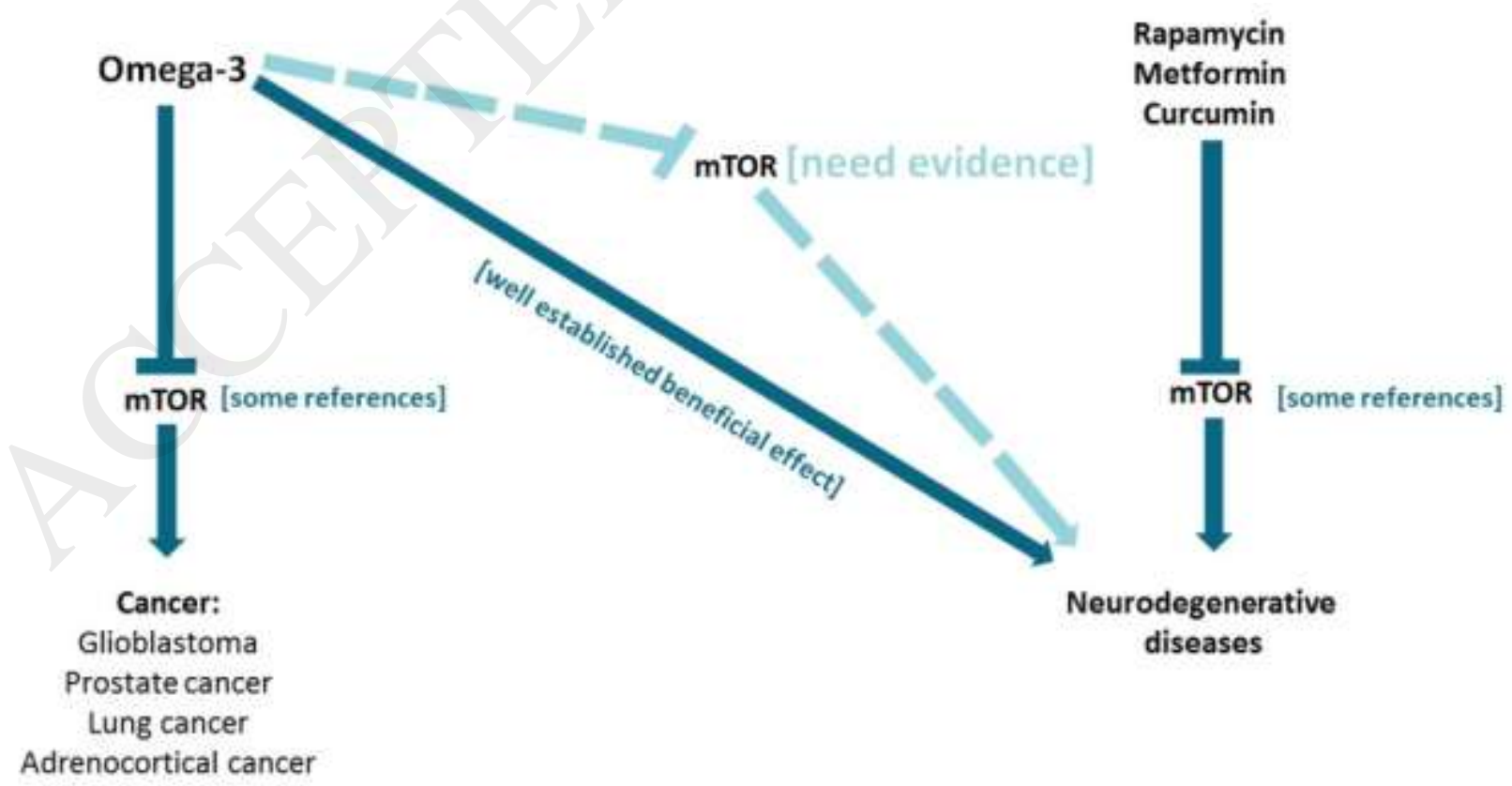




\begin{abstract}
Neurodegenerative diseases (NDs) such as Parkinson's (PD), Alzheimer's (AD), Huntington's disease (HD), and amyotrophic lateral sclerosis (ALS) cause significant world-wide morbidity and mortality. To date, there is no drug of cure for these, mostly age-related diseases, although approaches in delaying the pathology and/or giving patients some symptomatic relief have been adopted for the last few decades. Various studies in recent years have shown the beneficial effects of omega-3 poly unsaturated fatty acids (PUFAs) through diverse mechanisms including anti-inflammatory effects. This review now assesses the potential of this class of compounds in NDs therapy through specific action against the mammalian target of rapamycin (mTOR) signaling pathway. The role of mTOR in neurodegenerative diseases and targeted therapies by PUFAs are discussed.
\end{abstract}

Keywords: Neurodegenerative diseases, mTOR, omega-3, docosahexaenoic acid, eicosapentaenoic acid. 


\section{Introduction}

The progressive neuronal cell functional losses that arise from some kind of abnormal biochemical and structural changes or cell death is called neurodegeneration; while the disease associated with the processes are known as neurodegenerative diseases (NDs). The classical examples of the NDs are Parkinson's disease (PD), Alzheimer's disease (AD), Huntington's disease (HD), and amyotrophic lateral sclerosis (ALS) and that occur through the progressive neuronal degeneration accumulated over a period of time. Extensive researches in recent decades have been devoted to understanding the pathophysiological changes and risk factors of these chronic NDs [1]. One of the common risk factors is age and, in fact, these group of diseases are called age-relate neurodegenerative pathologies. Taking into account recent reports suggesting a significant increase in life expectancy in the very near future [2], a higher incidence of chronic NDs together with a lack of effective therapy would be a real concern.

Even though the molecular mechanisms responsible for NDs are not fully elucidated, dysregulation of several signal transduction pathways such as autophagy and endosomallysosomal [3], AMPK [4], p53 [5], P38 MAPK [6], JAK/STAT [7], PI3K/AKT [8], mTOR [9] etc., have been shown to be associated with these disorders. Within these pathways, mammalian target of rapamycin (mTOR), has been extensively studied in the context of aging and agerelated NDs. The mTOR has a key role in important cellular processes including cell survival, protein synthesis, mitochondrial biogenesis, proliferation, apoptosis, autophagy, etc. [10,11], and whose dysregulation can promote the initiation and progression of NDs. Since classical NDs has special features of accumulating abnormal misfolded or toxic proteins which regulates autophagy and cell fate, targeting mTOR may have important consequences on therapy against NDs. mTOR pathway in normal conditions inhibits autophagic mechanisms, which are necessary to degrade 
and eliminate abnormal or aggregated proteins [71]. Therefore, mTOR inhibitors may represent an interesting therapy for this kind of diseases by inducing autophagy or regulating apoptotic processes (Bove et al., 2011). In fact, classic mTOR inhibitors such as rapamycin or metformin have been reported to improve the neuronal damage in human and animal models of NDs [12]. Another important approach to fight against NDs are the use of natural products/compound including antioxidants [13], flavonoids [14], polyphenols [15], and polyunsaturated fatty acids (PUFAs) [16]. The omega-3 PUFAs represent a wide-range of unsaturated fatty acids which are often claimed to have numerous health benefits [17]. The best studied omega-3 FAs are docosahexaenoic acid (DHA), eicosapentaenoic acid (EPA), and $\alpha$-Linolenic acid (ALA). Structurally, the omega-3 group of FAs (Fig 1, drawn following the gguidelines for preparing color figures [18] is characterized by having the first double bond at position 3 of the terminal carbon or methyl group which is designated as omega ( $\omega$ or $n)$. However, the most common nomenclature of these compounds is the numbering starting from the carbonyl acid carbon assigned as carbon-1 and as shown in Fig. 1. Omega-3 FAs differ from each other by the total number of carbon groups in the molecule and amount and position where double bonds are formed. The essential oils of the higher plants are the main source of ALA while fish oils and other marine animal fats are the main sources of DHA and EPA. Hence, the Mediterranean dietary pattern, rich in vegetables and fish oils/products along with algae as the primary producers of EPA and DHA, have been advocated as a healthy diet option in recent years $[19,20]$.

Omega-3 PUFAs have a central role in the maintenance of cerebral functions and brain development contributing to neurogenesis and neuroplasticity. Moreover, these PUFAs also exert significant protective effects against inflammatory damage to the neurons and glial cells. Among 
the omega-3 fatty acids, the EPA has been reported to show the best promising effects as antidepressant agent [21,22]. Omega-3 PUFAs also have beneficial effects on cardiovascular diseases, as lipid lowering [23], antihypertensive [24] and antiinflammatory effect via modulation of cytokines and adhesion molecules expression [25]. These antiinflammatory properties have been well demonstrated in various animal models [26-29]. Moreover, omega-3 PUFAs reduce the risk or incidence of autoimmune diseases such as type 1 diabetes [30], multiple sclerosis [31], lupus erythematosus [32], psoriasis [33] and rheumatoid arthritis [34,35]. Mounting evidence has shown that omega-3 PUFAs can improve mental disorders such as schizophrenia and bipolar disorder [36]. The negative correlation between omega-3 PUFAs consumption and risk for cancer including pancreatic [37], colon [38], breast cancer [39] have been documented. Previous review articles also showed the potential of omega-3 PUFAs in diabetes retinopathy and other pathologies [40,41]. Omega-3 PUFAs, particularly DHA, have protective role in retina [42]. In addition, to the modulation of cytokine and adhesion molecules, the antiiflamatory effects of omega-3 PUFAs are associated to their incorporation in cell membrane phospholipids, contributing to the decrease in the production of proinflammatory omega-6 mediators [43]. Omega-3 PUFA are also important for the generation of antiinflammatory factors, such as neuroprotection D1 (NPD1) [44]. Recent evidences reported that omega-3 PUFAs can act as negative regulators of PI3K/Akt pathway which, in turn, results in mTORC1 inhibition [45]. In this sense omega-3 PUFAs could be interesting agents to prevent the initiation and progression of NDs.

The aim of this review is to overview the potential of omega-3 PUFAs as therapy for NDs through a possible specific action against the mTOR signaling pathway. Here, we summarize the 
main concepts of neurodegeneration, the role of mTOR in ND, and therapeutic implications of targeting mTOR pathway with omega-3 PUFAs.

\section{Hallmark of Neurodegeneration: Protein misfolding and precipitation.}

Neurodegenerative diseases (NDs) such as PD, AD, HD, and ALS cause significant world-wide morbidity and mortality. Hence, accumulation of deleterious changes through aging process is the main factor associated with many NDs [46]. The most common form of NDs is AD, which is characterized by a loss of memory in the older age group and account to over $60 \%$ of all forms of dementia cases [47]. As with many other NDs, protein misfolding and precipitation are the hallmark of $\mathrm{AD}$, the key player being the amyloid $\beta(\mathrm{A} \beta)$ peptides [48]. In addition to the presence of extracellular amyloid plaques composed of aggregated peptides, AD is characterized by intracellular neurofibrillary tangles comprising the microtubule-associated protein tau [49]. A $\beta$ peptides derive from the proteolytic cleavage of the amyloid precursor protein (APP) by aspartyl-proteases and secretases [50]. The link between $\mathrm{A} \beta$ peptides aggregation and inflammation and oxidative stress in the Alzheimer's brain has been established [51-54]. The main group affected in $\mathrm{AD}$ appear to be those of the cholinergic type that are closely linked to memory storage and retrieval [55,56]. PD is a cognitive and motor dysfunction characterized by the degeneration or loss of dopaminergic neurons [57,58]. The key pathological hallmark of PD is the appearance of Lewy bodies which derive from the progressive deposition of protein inclusions of $\alpha$-synuclein and ubiquitin leading to cell death (apoptosis or necrosis). ALS is a complex disorder which has the special feature of degenerated motor neurons, followed by muscle weakness, paralysis, and finally, death [59]. The basis of ALS is multifactorial and comprises genetic mutations with more than 20 genes involved, and epigenetic and 
environmental risk factors. The misfolding of the antioxidant enzyme, superoxide dismutase (SOD), has also been linked to ALS [60,61] while prion proteins are known to be involved in a range of spongiform encephalopathy diseases [62,63]. HD is a progressive neurodegenerative disease which has a wide variety of symptoms including movement, cognition and behavior [64]. The disorder is an autosomal-dominant neurodegenerative consequence of a genetic mutation in the HTT gene leading to ubiquitous expression of mutant huntingtin protein [65]. The NDs could also arise from a range of other acute (e.g., accident or direct form of physical injury to the CNS) or chronic diseases. A number of cardiovascular disease such as hypertension could also lead to stroke and results in significant neuronal changes and/or death [66]. The common pathology of NDs involve oxidative stress and inflammatory cascades through orchestrated cell-cell interaction including the immune cells in the central nervous system, such as the microglia [67].

\section{The mTOR signaling pathway}

Mammalian target of rapamycin (mTOR) has been shown to be a master regulator of cell proliferation as well as cellular metabolism. mTOR can be found in two multi-protein complexes: mTORC1 and mTORC2 [10]. The mTORC1 core complex contains mTOR, regulatory associated protein of TOR (raptor), DEP-domain containing mTOR interacting protein (DEPTOR), proline-rich Akt substrate 40kDa (PRAS40), and mammalian lethal with sec-13 protein 8 (mLST8). On the other hand, mTORC2 contains mTOR, mLST8, DEPTOR, rapamycin insensitive companion of mTOR (rictor), protein observed with rictor (Protor), and stress-activated protein kinase-interacting protein 1 (mSin1) [68]. Rapamycin, which was found to exert immunosuppressive and anti-proliferative activities can inhibit the activation of mTORC1 by binding to FK506-binding protein 1A, $12 \mathrm{kDa}$ (FKBP12), and prevent mTORC1 
formation $[69,10]$. The important upstream molecules of mTORC1 are PI3K/AKT and Ras/Erk, which are activated by growth factors like insulin. These pathways can activate mTORC1 by phosphorylation-dependent inhibition of TSC1/TSC2 complex. The TSC1/TSC2 complex has inhibitory effect on GTPase Rheb, which activates mTORC1. The AKT also inhibits the PRAS40 by phosphorylation, which negatively regulates mTORC1 [70]. The IкB kinase $\beta$ (IKK $\beta$ ) in response to pro-inflammatory cytokines like tumor necrosis factor- $\alpha$ (TNF $\alpha$ ), can phosphorylate TSC1 at Ser487 and Ser511, thus attenuates its inhibitory effect on mTORC1 [68]. Other signals that affect mTORC1 activity are hypoxia and low energy stress. AMPactivated protein kinase (AMPK) which is activated in low energy stress, phosphorylates TSC1 and promotes its inhibitory effect on Rheb, thus inhibiting mTORC1 activity. Also, AMPK can phosphorylate raptor, and inhibit the pathway [71].

The most important downstream effectors of mTORC1 are S6 kinase 1 (S6K1) and eukaryotic inhibition factor eIF4E binding protein 1 (4E-BP1). The mTORC1 phosphorylates S6K1 at mRNAs translation with a 5'-terminal oligopolypyrimidine (5'-TOP). Phosphorylation of S6K1 by mTORC1 promotes the phosphorylation of eIF4B and S6, which are components of the translation initiation complex $[69,70]$, as well as phosphorylation of EF2K, which through phosphorylating elongation factor-2 (eEF2) can regulate the translation of elongation step [72]. Another important effect of mTORC1 is the capability to inhibit mTORC2 and insulin receptor substrate (IRS). Recently, Cano and colleagues summarized other important downstream targets of S6K1 such as eIF4B, EF2K, BAD1, RafB/PKCe, MDM2, hnRNPs, Rictor or SKAR, as well as molecular mechanisms associated with S6K1 dysregulation have notable implication in aging and age-related diseases [73]. In addition to the mTORC1, the serine/threonine kinase p70S6K1 can also be activated by PDK1, MAPK and SAPK. The second main target of mTORC1 target is 
4EBP1 which binds to eukaryotic translation initiation factor 4E (eIF4E) and inhibits its activity. mTORC1-mediated phosphorylation of 4EBP1 increases the dissociation of 4EBP1/ eIF4E complex and leads to the initiation of translation.

As concern mTORC2, growth factors can activate it via the PI3K signaling pathway, increasing the association between mTORC 2 and ribosomes. Some of the mTORC 2 targets are PKC- $\alpha$, AKT and the GTPases Rac and Rho. The mTORC2 is involved in cellular metabolism and cell shape such as actin by PKC- $\alpha$ and Rho GTPase and in cellular proliferation by regulation of AKT. mTORC2 phosphorylates AKT at position Ser473, which promotes PDK1-mediated phosphorylation of AKT at The308, thus leading to full activation of AKT. Phosphorylation of AKT by mTORC2 is necessary to act on some of its targets such as forkhead box O1/3a (FoxO1/3a), while for others like TSC2 and GSK3- $\beta$, phosphorylation is not needed. The FoxO1/3a is also phosphorylated by SGK1, which is activated by mTORC2 [74]. The mTORC2 pathway is generally less clear than the mTORC1 $[10,70]$.

\section{1. $\mathrm{mTOR}$ and autophagy process}

Another important function of mTOR is its ability to modulate autophagy via different signaling pathways (Fig 2). Autophagy is a cellular digestion mechanism that recycles components in the cytoplasm to eliminate damaged molecules and non-functional organelles [75]. In this process proteins and organelles are delivered to autophagosomes that fuse with lysosomes for degradation [70]. It has been evidenced that inhibition of mTORC1 increases autophagy, while stimulation of mTORC1 decreases the process [76]. On the contrary, mTORC2 seems to indirectly suppress autophagy via phosphorylation of Akt resulting in Akt/mTORC1 signaling activation [77]. Diverse investigations reported that mTORC1 inhibits the autophagy-initiating 
UNC-5 like autophagy activating kinase (ULK) complex formation by promoting the phosphorylation of complex component ULK1/2. Activated ULK1/2, then, phosphorylates ATG13 (autophagy-related gene 13) and FIP200 (focal adhesion kinase family-interacting protein of $200 \mathrm{kDa}$ ) leading to the suppression this kinase complex essential to initiate autophagic process [78-80]. In addition, it was also reported that mTORC1 indirectly inhibits autophagy by preventing the ubiquitination of ULK1 through phosphorylating autophagy / Beclin-1 regulator 1 (AMBRA1) [81]. mTORC1 also inhibits autophagosome formation through phosphorylation of ATG14L in the VPS34 complex, a class III PI3K, which reduces the kinase activity of VPS34 [82]. Another mechanism responsible for mTORC1 mediated autophagy regulation is at transcriptional level through phosphorylating and inhibiting the activity of the transcription factor EB (TFEB), which is a principal regulator of lysosomal biogenesis and autophagic processes [83].

\section{2. mTOR and chronic diseases}

Several studies have been evidenced a relation between mTOR and diverse diseases. In this sense, a role of mTOR and their downstream targets has been found in cancers $[84,85]$. Over activity in PI3K and mutation in TSC1/2, LKB1 and PTEN genes, which are tumor suppressor genes, affect mTOR signaling pathway in cancers [68]. Obesity, an important risk factor for diabetes and many cancers like endometrial, has been shown to be linked to excessive activity of AKT/mTOR signaling pathway. Metformin, a common anti-diabetic therapeutic agent, has inhibitory effect on cancer cells by activation of AMPK through LKB1 signaling pathway leading to mTOR suppression [86]. In addition, metformin was also capable to inhibit mTOR and cell-cycle arrest via REDD1, independent of AMPK [87]. Chronic activation of mTOR due 
to high level of nutrients, results in non-alcoholic fatty liver disease [88]. The mTORC1 has also positive role on the size and function of pancreatic $\beta$-cell, but chronic activity of mTORC1 has negative effect on insulin receptor substrate $1 \& 2$ and leads to apoptosis in pancreatic $\beta$-cell $[86,10]$. Moreover, since mTORC1 is negative regulator of autophagy, which is one of the pathways to degrade misfolded proteins and defective autophagy is associated with multiple neurodegenerative diseases [89,90], studies have shown that mTORC1 inhibitors such as rapamycin increase autophagy and clearance of toxic proteins involved in NDs [10,91].

\section{Role of $\mathbf{m T O R}$ in neurodegenerative diseases}

The common feature of neurodegenerative disorders, such as $\mathrm{PD}, \mathrm{AD}$ and $\mathrm{HD}$, is the accumulation of toxic proteins in neurons which causes neural damage and cell death. Autophagy is necessary for clearance of misfolded proteins to decrease their aggregated load and, consequently, can reduce the neurodegeneration associated consequences. Taking into account that mTORC1 negatively regulates autophagy that inhibits the degradation of misfolded proteins accumulating in neuronal cells, over activity of mTORC1 can lead to neural damage. Hence, mTOR inhibitors may have a protective role against NDs [10,91]. Upregulation of autophagy is a potential therapeutic strategy against several neurodegenerative diseases [92-95]. However, hyperactivation results in complete stoppage of autophagy and leads to accumulation of toxic proteins such as tau and $A \beta$, which is the major cause of NDs, as seen in the development of epilepsy or epileptogenesis [96]. The mTOR signaling is important for memory reconsolidation [97] as it regulate protein synthesis in neurons and also played critical role in maintaining synaptic plasticity underlying memory formation. The mTOR inhibition for long time may however cause complications, as mTOR control several cellular processes [98,99]. 
Thus, the regulatory role of mTOR signaling pathway is important for preventing major NDs as is shown in Table 1. Furthermore, the inhibition of mTOR could exert a protective effect on brain against inflammation. A study performed by Dasuri et al. indicated that Donepezil, an acetylcholinesterase inhibitor, decreases mTOR phosphorylation as well as the phosphorylation of its downstream targets, such as p-p70S6K, in the brain tissues of mice administrated high fat diet and has a protective effect against neuroinflammation [184].

\subsection{Alzheimer's diseases}

$\mathrm{AD}$ is a progressive cognitive neurodegenerative disease linked to accumulation of extracellular $\mathrm{A} \beta$ plaques and hyperphophorylated tau protein leading to the formation of intracellular neurofibrillary tangles $[100,101]$. Excessive activity of mTOR increases the activity of $\beta$ - and $\gamma$ secretase, which leads to the generation of A $\beta$ plaques from APP (amyloid precursor protein). Diverse studies using humans and animal models evidenced that mTOR activation is related to the malfunction of $A \beta$ elimination from the brain since mTOR-mediated inhibition of autophagy favors the accumulation of $A \beta$ [102-104]. In addition, a relationship has been observed between the immaturity of the autofagolysosomes and the accumulation of autophagic vacuoles (AV) that can contribute to the generation of $A \beta$. In this sense, activation of mTOR alters the autophagic process leading to the accumulation of immature forms of AVs [105]. mTOR also regulates tau phosphorylation, which leads to the development of intracellular filaments. In accordance with this effects, inhibition of mTOR by rapamycin could in a transgenic mouse model alleviate cognitive impairments as well as reducing the alterations associated with amyloid plaques accumulation and neurofibrillary tangles via autophagy activation [106,107]. 
Extensive studies have shown that in $\mathrm{AD}$, functional impairments of synaptic plasticity normally develops before neurodegeneration resulting in neuronal damage and/or lost $[108,109]$. mTOR integrates multiple inputs associated with nutrients, growth factors and the cellular energy status that result in its activation or inhibition being a crucial regulator between anabolic and catabolic processes [110,111]. Diverse investigations have evidenced that soluble oligomers of $A \beta$, derived from APP, are able to inhibit long-term potentiation (LTP) and cause deficits in learning and memory [112-114]. Ma and colleagues studied the association of mTOR signaling pathway with $A \beta$-induced synaptic dysfunction. The authors reported that in the hippocampus of animal models of $\mathrm{AD}$, the activity of mTOR was decreased, and when mTOR signaling was activated, the inhibition of LTP associated with $A \beta$ was recovered. In 3xTg mice model of AD without evidence of amyloid plaques and tangles, the mTOR-induction of autophagy with rapamycin have been reported to ameliorate cognitive deficits [115]. The chronic treatment with rapamycin reduced the progression of $\mathrm{AD}$ and increased autophagy which, in turn, reduced $\mathrm{A} \beta$ levels in the mouse model of the human amyloid precursor protein (PDAPP) [116]. Thus, mTOR pathway regulates $A \beta$-related synaptic dysfunction in $A D$ [113]. Other studies also reported that mTOR activation induces tau hyperphosphorylation contributing to the progress of $\mathrm{AD}[117,118]$. Rapamycin treatment reduces the phosphorylation of tau (at Ser214) via regulating cAMPdependent kinase. Also, autophagy induction could improve the clearance of the hyperphosphorylated tau $[119,120]$.

\subsection{Down syndrome (DS)}

DS is regarded as a frequently-occurring chromosomal abnormality which leads to intellectual disorder or disability $[121,122]$. The neurophysiology of AD with respect to DS is multifaceted 
and includes impaired functions of mitochondria [123], defects in neurogenesis [124], high generation of oxidative species [125], impaired autophagy networks and proteostasis [126] due to triplication of chromosome 21. Gene products at Chromosome 21 are recognized as principal neuropathogenic moieties in the development of DS [127,128]. Moreover, DS after age 40-50 has considerable AD-like neuropathology and individuals present notable signs of dementia. Thus, two principal biomarkers of the etiology of AD (senile plaques that are mostly composed of fibrillar $A B$ peptides and hyperphosphorylated tau protein) appear to operate through the mTOR signaling system. Moreover, it has been reported that inhibition of mTOR decreases the tau pathology [106].

\subsection{Parkinson's disease}

In PD, the pathology is associated with deletion of dopaminergic cells in central and peripheral neurons, associated to the presence of lewy bodies formation with the major toxic protein component of $\alpha$-synuclein ( $\alpha$-syn), that is phosphorylated in serine residue at position 129 [129]. In vitro studies have shown that metformin reduces phospho-Ser129 $\alpha$-syn through activation of the AMPK which inhibits mTOR activity and decreases the levels of phosphorylated forms of mTOR downstream targets including p-S6K [69]. Inhibition of mTOR leads to PP2A activation, a neuroprotective protein phosphatase, which dephosphorylates phospho-Ser129 $\alpha$-syn. Rapamycin has also shown to display similar effect to metformin reducing the formation of lewy bodies [130]. In animal models of PD, rapamycin mediated inhibition of mTOR also exerts neuroprotection through blockade of expression of stress response protein RTP801 and survivalpromoting kinase Akt [131]. 
Moreover, it has been observed that the mTOR pathway showed central role in dopaminergic neurons activity in PD [132,133] [134]. There is increasing evidence to suggest that activation of $\mathrm{PI} 3 \mathrm{~K} / \mathrm{Akt} / \mathrm{mTOR}$ pathway can regulate neuronal development, survival and differentiation, and it also played a crucial role in synaptic plasticity $[9,135]$. Nakasoand colleagues observed in a cellular model of PD that the neuroprotective effect of caffeine was caused by the activation of the PI3K/Akt pathway [136,134]. Additionally, administration of $\mathrm{MPP}^{+}$(1-methyl-4phenylpyridinium) decreased the phosphorylation of mTOR and its canonical substrate, p70S6K, in control and G2019S LRRK2-mutant skin fibroblasts [137,134]. The PI3K/Akt/mTOR genes in the SH-SY5Y dopaminergic cells also provide a reference gene framework for researchers working in PD. The expression pattern will further offer useful clues about the function of the signaling pathway during PD pathogenesis and possible neuroprotection options $[138,134,139]$. However, mTOR has a controversial sort of role as various results presented neuroprotective as well as neurotoxic effects in different studies. For instance, rotenone, a known PD toxin, caused downstream regulation of mTOR and decreased cell viability in different PD models [140,141]. Lysosomal dysfunction appears to contributes to rotenone's neurotoxicity $[142,143]$ and could be antagonized by pretreatment with rosuvastatin [144]. On the other hand, there are evidences suggesting that upstream regulation of mTOR causes partial prevention in neuronal cell loss provoked by PD toxin $[145,146]$. Therefore, future studies are warranted to explore the exact role of mTOR signaling pathway in PD.

\subsection{Huntington's disease (HD)}

$\mathrm{HD}$ is an autosomal dominant neurodegenerative disease, which is characterized by neurodegeneration of the basal ganglia and cortex linked to the aggregation of huntingtin protein. 
Mutant huntingtin protein has expansion of CAG (cytosine-adenine-guanine) triplet repeats, which is not cleared from cells and leads to neural death. In vivo studies has indicated that rapamycin mediated inhibition of mTOR can relieve the symptoms of HD by increasing autophagy and clearance of mutant huntingtin [147,91]. Evidence also supports that mTOR inhibitors have protective roles in neurodegenerative diseases in animal models, but more studies are needed using mTOR inhibitors.

\subsection{Amyotrophic lateral sclerosis (ALS)}

ALS is associated to the progressive loss of functional motor neurons, and to the formation of misfolded protein inclusions in neurons [148]. Diverse studies using SOD1G93A mice (which mimics the most usual familial cause of ALS), evidenced that the treatment with rapamycin failed to protect against the disease progression even aggravated motor neuron loss $[149,150]$. Similar results were obtained using rapamycin in a mouse model of ALS induced by mutant valosin protein [151]. On the contrary, the treatment with trehalose, an mTOR-independent activator of autophagy prolonged motor neuron survival and reduced the autophagic flux defect in a SOD1G93A mouse model of ALS [152]. Taking together these results suggest that in ALS mTOR seems not to be an adequate target.

\section{Omega-3 fatty acids and neurodegeneration}

The broad protective effects of omega-3 PUFAs in the CNS function have been well recognized (Table 2 and Table 3). As described above, $\mathrm{AD}$ is a devastating neurodegenerative disease with over-expression of $A \beta$ peptide, extensive inflammation and neuronal cell death $[153,154]$. Omega-3 PUFAs have been shown to improve mental health and cognition including in 
Alzheimer's disease [155]. They also attenuates the symptoms of attention-deficit/hyperactivity disorder (ADHD) and improve attention and the ability to complete tasks in children [156]. Multiple reports have clearly demonstrated that omega-3 PUFA can prevent or treat psychopathologies such as "emotional depression," "bipolar disorder," "schizophrenia," and AD [36].

The DHA and EPA treatment have significant anti-inflammatory effects in AD [157]. The EPA showed effect through BDNF over expression while DHA caused down regulation of TNF- $\alpha$ $[158,159]$ leading to phagocytosis and anti-inflammatory effects. The potential role of PUFAs in immunoregulation has also been reported in patients with AD suplemented with omega-3 PUFAs $[160,161]$

Both $\mathrm{A} \beta$ and tau aggregates results in increasing neuronal death, stress and defects in neuronal pathways, and leads to neurodegenerative disease. Omega-3 was found to attenuate the disease condition and enhances neuroprotection by increasing the expression of BDNF and also high affinity BDNF receptor (TrkB). During neurodegeneration disease such as $\mathrm{AD}$ and $\mathrm{PD}$, the omega-3 concentration were shown to decrease in the brain and resulted in more serious consequences. In an experiment where three transgenic $\mathrm{AD}$ animal model were used to evaluate the impact of omega-3 on neurological disorders, adding omega-3 in diet was found to revert the condition via inhibitory accumulation of $\mathrm{A} \beta$, hyperphosphorylation of tau and improve the cognitive deficits [162].

$\mathrm{A} \beta$ accumulation is the major cause of $\mathrm{AD}$ causing oxidative damage, inflammation of neurons and also phosphorylating tau protein, [163]. In a study, a transgenic animal model of memory loss and A $\beta$ depletion (Tg 2576 mouse) exposed to PUFA (1g/kg/day), dietary intake for 16-20 months, reduces the $\mathrm{A} \beta$ accumulation $[162,164]$ and exert neuroprotective activity. DHA 
treatment $(0.98 \mathrm{~g} / \mathrm{kg} / \mathrm{day})$ for 6 to 10 months in transgenic animal model (APPs we/PSIdE9) decreases $A \beta$ accumulation [165]. In similar study, the intraneuronal $A \beta$ concentration along with tau accumulation and phosphorylation decreases, when DHA incorporated to the diet $(2.3 \mathrm{~g} / \mathrm{kg} /$ day) was given for 9 months in the $3 \times \mathrm{Tg}$-AD mouse model [166]. Also, NPDI derived from omega-3 was found to protect neurons from $\mathrm{A} \beta$ direct apoptosis in $\mathrm{HN}$ culture cells $[167,168]$.

Kusat and colleagues studied the effect of omega-3 along with betaine for possible protection against alcohol induced neurodegeneration [169]. In their study, female rats in the prenatal and postnatal stages were exposed to high alcohol concentrations $(25-75 \mathrm{~mL}$ ethanol) that cause fetal alcohol syndrome (FAS) [170-172]. When omega-3 PUFAs in modified diet were administered during pregnancy and after delivery, they provoked a significant reduction in brain necrosis induced by excessive ethanol intake. It is already known that neonatal rat brain is highly sensitive to ethanol and necrosis is regard as the primary death caused after acute neonatal head injury [173], which was also noted in histopathalogical studies [174].

Various studies have confirmed the role of omega-3 in preventing neurodegeneration [175-177], along with clinical trials proven its effectiveness [178-181]. A mechanistic activity of omega-3 PUFA in protecting NDs has been shown in Figure 3.

PUFAs have been shown to have critical role in cerebral functions and brain development. For example, DHA in the brain contributes in gene expression, neurogenesis, neuroplasticity, neuron differentiation, survival, oxidative metabolism, learning and memory process $[155,182]$. The EPA and DHA diet in rats during post-natal development, can increase SOD [183].The EPA can also inhibit JNK activation, which phosphorylate and inhibit the antiapoptotic bcl-2 protein by proliferator activating receptors (PPAR- A $\alpha$ ) [184]. The DHA decreases the production and 
aggregation of $\mathrm{A} \beta$ from amyloid precursor protein. The DHA diet for 8-10 months in Aged $3 \times \mathrm{Tg}-\mathrm{AD}$ mice also improved cognition and prevent the pathological effect of $\mathrm{mpp}^{+}$onnigral cells and striatum. Ethyl-EPA diet in MPTP-probencid mouse model of PD can also prevent some of the PD symptoms such as hypokinesia but it failed to prevent the decreation of nigrostriatal dopamine [185]. In mouse model of HD, oral administration of PUFAs can prevent motor deficits [182]. The Rthyl-EPA in YAC128 HD mice has also been shown to decrease motor deficits [182]. On the other hand, DHA-enriched diet can increase the number of dendrite spine in hippocampus of animals. Moreover, there is a negative association between homocyteine levels and DHA in plasma. Homocysteine can act as a glutamate agonist on NMDARs and has excitotoxicity effect and neurodegeneration [186].

\section{6. mTOR as a new omega-3 target in NDs therapies?}

As reported above, in section 4, mTOR seems to be an interesting candidate for some types of NDs, such as AD, SD, PD and HD. In scientific literature, as described in section 5, the omega-3 PUFAs role as neuroprotective agent is well recognized. Some references reported mTOR as an omega-3 target in different pathological conditions, but in NDs there aren't studies that prove mTOR as an omega-3 target. Nevertheless, considering the promising evidence regarding the involvement of mTOR in other chronical pathologies, studies on the omega-3 beneficial activity in NDs through mTOR inhibition are strongly needed.

\subsection{Omega-3 mechanism of action in NDs}

Omega-3 PUFAs protect neurons and related disorders through mTOR signaling pathway. Upstream of mTOR, i.e., PI3K/Akt pathway was activated by omega-3 PUFAs which is central 
for cell survival. Accordingly, omega-3 PUFAs supplementation facilitates Akt translocation to the membrane for activation and this process is blocked under serine-depleted conditions, suggesting that omega-3 PUFAs-derived phosphatidylserine (PS) is necessary for this effect [187]. Omega-3 PUFAs are suggested to be the best substrate for PS synthesis which prevents normal cell death and is one of the potent neuroprotective agents. The serine/theonine Akt kinase is an important enzyme in cell survival [188] and it played important role in mediating the protective effect of omega 3 in neuronal cells $[189,190]$. The reduction in activity of Akt kinase pathway leads to the apoptotic death, which can be prevented by omega-3 via phosphorylation/ activation of Akt kinase. The PS is also involved in signaling event of kinases such as protein kinase C, Raf-1 kinase [187] and Akt [190] . In addition to the effects via mTOR, diverse evidenced showed that the omega-3 also form neuroprotectin D1 (NPD1), a new DHA-derived 10,17S-docosatriene, which prevents the $\mathrm{A} \beta$ secretion and, consequently, represses $\mathrm{A} \beta$ triggered activation of proinflammatory genes and activation of antiapoptosis genes [191]. In AD mouse model and human neuroglial (HNG) cells cultured with $A \beta$ protein, the role of omega-3 derived NPD1 was also investigated [192]. The results showed that NPD1 treatment prevented the A $\beta$ driven expression of proinflammatory enzymes (COX-2 and B-94), downregulated apoptosis and reduced neuronal cell death. However, diverse studies using human retinal pigment epithelium cells reported that NPD1 leads to cell survival after challenged with oxidative stress, at least in part, via activating the PI3K/Akt and mTOR/p70S6K pathways [193,194]. Similar protective effects of omega-3 were recorded by Ma and coworkers in the survival in cultured hippocampal neurons by upregulating the expression genes with anti-apoptotic functions, repressed proinflammatory genes and inhibit the phosphorylation of IRS-1 by different pathways including PI3K/Akt/mTOR and tau by $\mathrm{A} \beta[195]$. 
The mechanism of omega-3 was studied in some of experiments. For instance, omega-3 enriched diet which has direct effect on signaling pathway (PI3K/Akt/mTOR), increased the neurotrophin levels like NGF (Nerve growth factor) and BDNF and thus, improved cognition function [196]. These neurotrophins regulate/stimulate the transcription and release of the vascular endothelial growth factor (VEGF) [197]. VEGF represents a major pro-angiogenesis protein [198]. VEGF is regulated by HIF-1 alpha levels which, in turn, depend on PI3K/Akt/m+TOR pathway. Activation of mTOR pathway by BDNF and NGF neurotrophins, phosphorylates the two downstream effectors P7056K and 4E-BP1, which regulate and promote angiogenesis [199].

Autophagy is an important part of cell cycle and has a role in preventing cellular damage by elimination of toxic protein aggregates, which causes cell death. In case of neuronal death, these toxic proteins result in increased $A \beta$ and tau concentration. The mTOR signaling pathway mainly regulates autophagic process, which is regulated by growth factors, cellular stress and nutritive deficiency. The PI3K/Akt pathway modulates the mTOR signaling pathway and thus played role in modulating the disorders. In one way, this pathway enhances the autophagic events of $A \beta$, on the other side hyperactivation of pathway will also leads to neuronal death. Thus, the regulation of this process is important and omega-3 PUFAs play a crucial role as proved by several studies.

\subsection{Targeting mTOR by omega-3 in pathological conditions}

Some studies showed that mTOR inhibition represent one major mechanisms whereby omega-3 PUFAs exert beneficial effects towards different types of pathologies.

Both in vitro and in vivo studies, have reported mTOR as an omega-3 target in different chronical pathological conditions, such as glioblastoma [200], prostate cancer [173], lung cancer 
[201], adrenocortical cancer [202]. Moreover, omega-3 PUFAs trough mTOR inhibition resulted to be active in renal ischemia reperfusion injury attenuation [183], in the protection against systemic inflammation and insulin resistance through the inhibiting the activation of NLRP3 inflammasome, as well as subsequent caspase- 1 activation, and the secretion of cleaved IL-1 $\beta$ [203].

Previous study has shown that AMPK and TSC1/2 knockdown by siRNA slightly decrease the inhibitory effect of DHA on mTORC1. The DHA can stabilize the mTOR-raptor complex and decrease its activity. The omega-3 PUFAs decrease the IGF1R and increase PTEN levels, negative regulator of PI3K/Akt pathway which activates mTORC1 [204]. In an in vitro study performed on isolated $\mathrm{CD} 4^{+} \mathrm{T}$ cells from spleen tissues from NOD mice, while, omega-3 PUFAs treatment inhibited the differentiation of CD4+ T cells into Th1 cells by inhibiting TORC1, thus having beneficial effects in autoimmune diseases such as type 1 diabetes [205]. In one study, DHA has been shown to increase the level of intracellular ROS. It was proposed that ROS inactivate AKT/mTOR signaling and, consequently, both autophagy and apoptosis are activated in cancer cells [206]. The LKB1 gene expression and its activity are also stimulated by DHA. In mammary epithelial cells expressing LKB1, the treatment with for $24 \mathrm{~h}$ evidenced increased AMPK phosphorylation which leads to the inhibition of the mTOR pathway [84].

Recently, diets rich in EPA and DHA have shown beneficial effects in muscular activity when studied in older American citizens causing over expression of muscle mTOR and p70s6k phosphorylation [207] and strongly support memory loss in AD [208]. Hence, evidence suggest that omega-3 PUFAs reduce the over activity of mTOR, but additional clinical trials would be more helpful to investigate the involvement of mTOR pathway and mTOR inhibitors like n-3 PUFAs on patients with neurodegenerative disorders. 
The mTOR can be a useful mechanistic pathway for targeting drug resistance in anticancer therapy [209]. The mTOR inhibitor showed marked reduction in the growth of melanoma cells, support apoptosis and prevent necrosis [210,209]. DHA increases autophagy in metastatic adenocarcinoma cell lines (human PC3 and DU145) by mitochondrial ROS accumulation [206,184,211]. An in vitro observation on MCF7 cells showed that DHA elevated the expression and the activity of LKB1, and this increase also phosphorylated and activated AMPK, a negative regulator of mTOR. As in LKB1 knockdown MCF7 cells, pS6 expression, a downstream target of mTOR, did not alter beside the control [212]. Corticosteroids elicited muscular atrophy by hitting the proteasomal and lysosomal systems [213,214] and mediating through molecular regulation of muscular trophysm, such as through the IGF-1/PI-3K/Akt/mTOR [215]. Polyunsaturated fatty acids caused significant renal protection through various mechanisms including autophagy. In fat-1 mice, omega-3 accumulation evoked renal protection and better kidney functioning possibly acting through activation of AMPK which causes downstream regulation of mTOR singling pathway [216].

\section{Conclusion}

In conclusion, NDs, such as $\mathrm{AD}, \mathrm{PD}$ and $\mathrm{HD}$, remain major age-related disorders with significant world-wide morbidity and mortality. The lack of effective therapy for these diseases require adopting new strategies for the search of new drugs including those from natural sources that act through novel biological targets.

In this regard, the careful analysis of scientific literature carried out in this review showed that:

1) The identification of mTOR as significant regulator of cell cycle and cancer has been extended in recent years to NDs. In fact, growing evidences suggest the possible role of 
mTOR inhibitors as a new interesting therapy for NDs, due to their ability to induce apoptotic processes, which are necessary to degrade and eliminate abnormal or aggregated proteins;

2) It is well known that omega-3 PUFAs exert a protective role on central nervous system against numerous pathologies;

3) Both in vitro and in vivo studies have reported mTOR as an omega-3 target in different chronic and systemic pathological conditions.

Therefore, omega-3 PUFAs which are recognized as mTOR inhibitors in different chronic pathologies, might be also considered as mTOR inhibitory agents to develop new therapeutic strategies for NDs. This hypothesis should induce the researchers to deepen the study of the mechanism through which omega-3 PUFAs exert their protective action in NDs, focusing their attention on mTOR.

These studies as well as our knowledge on the mTOR signaling pathway regulation are however still in their infant stage and further studies and clinical trials on these promising dietary constituents should be strongly encouraged in the future. Thus, additional studies are needed to underline the omega-3 inhibitory activity on mTOR in NDs (Figure 4).

\section{Conflict of interests}

All Authors declared no conflict of interests. 


\section{References}

1. M. Agrawal, A. Biswas, Molecular diagnostics of neurodegenerative disorders, Front. Mol. Biosci. 2(2015) 54. doi:10.3389/fmolb.2015.00054

2. V. Kontis, J.E. Bennett, C.D. Mathers, G. Li, K. Foreman, M. Ezzati, Future life expectancy in 35 industrialised countries: projections with a Bayesian model ensemble, Lancet 389 (2017) 1323-1335.

3. D. Wang, C.C. Chan, S. Cherry, P.R. Hiesinger, Membrane trafficking in neuronal maintenance and degeneration. Cell. Mol. Life Sci. 70 (2013) 2919-2934. doi:10.1007/s00018-012-1201-4

4. M. Domise, V. Vingtdeux, AMPK in Neurodegenerative Diseases. In: AMP-activated Protein Kinase. Springer, 2016, 153-177.

5. J.R. Chang, M. Ghafouri, R. Mukerjee, A. Bagashev, T. Chabrashvili, B.E. Sawaya, Role of p53 in Neurodegenerative Diseases, Neuro-Degenerative Dis. 9 (2012) 68-80. doi:10.1159/000329999

6. S.A.L. Corrêa, K.L. Eales, The role of p38 MAPK and Its substrates in neuronal plasticity and neurodegenerative disease, J. Signal Transduct. 2012(2012)12. doi:10.1155/2012/649079

7. C.S. Nicolas, M. Amici, Z.A. Bortolotto, A. Doherty, Z. Csaba, A. Fafouri, P. Dournaud, P. Gressens, G.L. Collingridge, S. Peineau, The role of JAK-STAT signaling within the CNS, JAK-STAT 2 (2013) e22925. doi:10.4161/jkst.22925

8. L.Y. Wang, Z.J. Tang, Y.Z. Han, Neuroprotective effects of caffeic acid phenethyl ester against sevoflurane-induced neuronal degeneration in the hippocampus of neonatal rats involve MAPK and PI3K/Akt signaling pathways, Mol. Med. Rep. 14 (2016) 3403-3412.

9. A. Chen, L.J. Xiong, Y. Tong, M. Mao, Neuroprotective effect of brain-derived neurotrophic factor mediated by autophagy through the PI3K/Akt/mTOR pathway, Mol. Med. Rep. 8(2013) 1011-1016.

10. M. Laplante, D.M. Sabatini, mTOR signaling in growth control and disease, Cell 149(2012) 274-293

11. C.M. Hung, L. Garcia-Haro, C.A. Sparks, D.A. Guertin, mTOR-dependent cell survival mechanisms, Cold Spring Harb. Perspect. Biol. 4 (2012) a008771. doi:10.1101/cshperspect.a008771 
12. D.W. Lamming, L. Ye, D.M. Sabatini, J.A. Baur, Rapalogs and mTOR inhibitors as anti-aging therapeutics, J. Clin. Invest. 123 (2013) 980-989. doi:10.1172/jci64099

13. M. Decker, Hybrid molecules incorporating natural products: applications in cancer therapy, neurodegenerative disorders and beyond, Curr. Med. Chem. 18(2011) 1464-1475.

14. S.L. Costa, V.D.A. Silva, C. dos Santos Souza, C.C. Santos, I. Paris, P. Muñoz, J. Segura-Aguilar, Impact of plant-derived flavonoids on neurodegenerative diseases, Neurotox. Res. 30 (2016) 41-52.

15. C. Ramassamy, Emerging role of polyphenolic compounds in the treatment of neurodegenerative diseases: a review of their intracellular targets, Eur. J. Pharmacol. 545 (2006) 51-64.

16. F. Calon, G. Cole, Neuroprotective action of omega-3 polyunsaturated fatty acids against neurodegenerative diseases: evidence from animal studies, Prostaglandins Leukot. Essent. Fatty Acids 77(2007) 287-293.

17. E. Scorletti, C.D. Byrne, Omega-3 fatty acids, hepatic lipid metabolism, and nonalcoholic fatty liver disease, Ann. Rev. Nutr. 33(2013) 231-248.

18. W. Cave Jr, Dietary n-3 (omega-3) polyunsaturated fatty acid effects on animal tumorigenesis, FASEB J. 5 (1991) 2160-2166

19. S.D. Doughman, S. Krupanidhi, C.B. Sanjeevi, Omega-3 fatty acids for nutrition and medicine: considering microalgae oil as a vegetarian source of EPA and DHA, Curr. Diabetes Rev. 3 (2007) 198203.

20. T.C. Adarme-Vega, D.K.Y. Lim, M. Timmins, F. Vernen, Y. Li, P.M. Schenk, Microalgal biofactories: a promising approach towards sustainable omega-3 fatty acid production, Microb. Cell Fact. 11 (2012) 96-96. doi:10.1186/1475-2859-11-96

21. H. Mozaffari-Khosravi, M. Yassini-Ardakani, M. Karamati, S.E. Shariati-Bafghi, Eicosapentaenoic acid versus docosahexaenoic acid in mild-to-moderate depression: a randomized, double-blind, placebocontrolled trial, Eur. Neuropsychopharmacol. 23 (2013) 636-644. 
22. S. Jazayeri, M. Tehrani-Doost, S.A. Keshavarz, M. Hosseini, A. Djazayery, H. Amini, M. Jalali, M. Peet, Comparison of therapeutic effects of omega-3 fatty acid eicosapentaenoic acid and fluoxetine, separately and in combination, in major depressive disorder, Aust. N. Z. J. Psychiatry 42 (2008) 192-198. 23. R. Cazzola, S. Russo-Volpe, E.A. Miles, D. Rees, T. Banerjee, C.E. Roynette, S.J. Wells, M. Goua, K.W. Wahle, P.C. Calder, Age-and dose-dependent effects of an eicosapentaenoic acid-rich oil on cardiovascular risk factors in healthy male subjects, Atherosclerosis 193 (2007) 159-167.

24. M.A.B. Lozovoy, L.D. Bahls, H.K. Morimoto, T. Matsuo, I. Dichi, Blood pressure decrease with ingestion of a soya product (kinako) or fish oil in women with the metabolic syndrome: role of adiponectin and nitric oxide, Br. J. Nutr. 108 (2012) 1435-1442.

25. R. Marchioli, F. Barzi, E. Bomba, C. Chieffo, D. Di Gregorio, R. Di Mascio, M.G. Franzosi, E. Geraci, G. Levantesi, A.P. Maggioni, Early protection against sudden death by n-3 polyunsaturated fatty acids after myocardial infarction, Circulation 105 (2002)1897-1903.

26. P. Singer, H. Shapiro, M. Theilla, R. Anbar, J. Singer, J. Cohen, Anti-inflammatory properties of omega-3 fatty acids in critical illness: novel mechanisms and an integrative perspective, Intensive Care Med. 34 (2008) 1580.

27. R. Wall, R.P. Ross, G.F. Fitzgerald, C. Stanton, Fatty acids from fish: the anti-inflammatory potential of long-chain omega-3 fatty acids, Nutr. Rev. 68 (2010) 280-289.

28. A.P. Simopoulos, Omega-3 fatty acids in inflammation and autoimmune diseases, J. Am. Coll. Nutr. 21 (2002) 495-505

29. E. Mas, A. Barden, V. Burke, L.J. Beilin, G.F. Watts, R.C. Huang, I.B. Puddey, A.B. Irish, T.A. Mori, A randomized controlled trial of the effects of n-3 fatty acids on resolvins in chronic kidney disease. Clin. Nutr. 35 (2016) 331-336.

30. L.C. Stene, G. Joner, N.C.D.S. Group, Use of cod liver oil during the first year of life is associated with lower risk of childhood-onset type 1 diabetes: a large, population-based, case-control study, Am. J. Clin. Nutr. 78 (2003)1128-1134. 
31. S. Hoare, F. Lithander, I. van der Mei, A.L. Ponsonby, R. Lucas, A.I. Group, Higher intake of omega3 polyunsaturated fatty acids is associated with a decreased risk of a first clinical diagnosis of central nervous system demyelination: Results from the Ausimmune Study, Mult. Scler. 22 (2016) 884-892.

32. M.C. Borges, F.d.M.M. Santos, R.W. Telles, M.I.T.D. Correia, C.C.D. Lanna, Polyunsaturated omega-3 fatty acids and systemic lupus erythematosus: what do we know? Rev. Bras. de Reumatol. 54 (2014) 459-466.

33. G.M. Balbás, M.S. Regaña, P.U. Millet, Study on the use of omega-3 fatty acids as a therapeutic supplement in treatment of psoriasis. Clin. Cosmetic Investig. Dermatol. 4(2011) 73.

34. C. Lourdudoss, D. Di Giuseppe, A. Wolk, H. Westerlind, L. Klareskog, L. Alfredsson, R.F. van Vollenhoven, J. Lampa, Dietary Intake of Polyunsaturated Fatty Acids and Pain in spite of Inflammatory Control among Methotrexate Treated Early Rheumatoid Arthritis Patients. Arthritis Care Res. 70(2017)205-212.

35. L. Navarini, A. Afeltra, G.G. Afflitto, D.P.E. Margiotta, Polyunsaturated fatty acids: any role in rheumatoid arthritis? Lipids Health Dis. 16 (2017):197.

36. M.M. Pusceddu, P. Kelly, C. Stanton, J.F. Cryan, T.G. Dinan, n-3 polyunsaturated fatty acids through the lifespan: Implication for psychopathology. International Journal of Neuropsychopharmacology 19 (2016) pyw078.

37. M. Park, H. Kim, Anti-cancer Mechanism of Docosahexaenoic Acid in Pancreatic Carcinogenesis: A Mini-review, J. Cancer Prevent. 22 (2017) 1-5. doi:10.15430/jcp.2017.22.1.1

38. E. Theodoratou, G. McNeill, R. Cetnarskyj, S.M. Farrington, A. Tenesa, R. Barnetson, M. Porteous, M. Dunlop, H. Campbell, Dietary fatty acids and colorectal cancer: a case-control study. Am. J. Epidemiol. 166 (2007) 181-195.

39. C.J. Fabian, B.F. Kimler, S.D. Hursting, Omega-3 fatty acids for breast cancer prevention and survivorship, Breast Cancer Res. 17 (2015) 62. 
40. K.M. Connor, J.P. SanGiovanni, C. Lofqvist, C.M. Aderman, J. Chen, A. Higuchi, S. Hong, E.A. Pravda, S. Majchrzak, D. Carper, Increased dietary intake of $\omega-3$-polyunsaturated fatty acids reduces pathological retinal angiogenesis, Nat. Med. 13(2007) 868-873.

41. J. Hartweg, R. Perera, V.M. Montori, S.F. Dinneen, A.H. Neil, A.J. Farmer, (2008) Omega-3 polyunsaturated fatty acids (PUFA) for type 2 diabetes mellitus, Cochrane Database Syst. Rev. (2008)CD003205.

42. G. Querques, R. Forte, E.H. Souied, Retina and omega-3, J. Nutr. Metab. 2011(2011), 748361

43. E. Pauwels, D. Volterrani, G. Mariani, K. Kairemo, Fatty acid facts, Part IV: docosahexaenoic acid and Alzheimer's disease. A story of mice, men and fish, Drug News Perspect. 22 (2009) 205-213

44. NG Bazan, Neuroprotectin D1 (NPD1): a DHA-derived mediator that protects brain and retina against cell injury-induced oxidative stress, Brain Pathol. 15 (2005) 159-166

45. M. Liu, L. Zhou, B. Zhang, M. He, X. Dong, X. Lin, C. Jia, X. Bai, Y. Dai, Y. Su, Elevation of n-3/n6 PUFAs ratio suppresses mTORC1 and prevents colorectal carcinogenesis associated with APC mutation, Oncotarget 7 (2016)76944

46. T.O. Elufioye, T.I. Berida, S. Habtemariam, Plants-derived neuroprotective agents: Cutting the cycle of cell death through multiple mechanisms. Evidence-Based Complement. Alternat. Med. 2017(2017) 3574012.

47.

Society)

AAs

(2017)

https://www.alzheimers.org.uk/info/20027/news_and_media/541/facts_for_the_media.

48. G.M. Ashraf, N.H. Greig, T.A. Khan, I. Hassan, S. Tabrez, S. Shakil, I.A. Sheikh, S.K. Zaidi, M. Akram, N.R. Jabir, Protein misfolding and aggregation in Alzheimer's disease and type 2 diabetes mellitus. CNS Neurol. Disord. Drug Targets 13 (2014) 1280-1293.

49. M.O. Grimm, J. Mett, T. Hartmann, The Impact of Vitamin E and Other Fat-Soluble Vitamins on Alzheimer's Disease. Int. J. Mol. Sci. 17 (2016) 1785

50. E. Norstrom, Metabolic Processing of the Amyloid Precursor Protein-New Pieces of the Alzheimer's Puzzle, Discov. Med. 23 (2017) 269-276 
51. E. Tönnies, E. Trushina, Oxidative stress, synaptic dysfunction, and Alzheimer's disease, J. Alzheimer's Dis. 57 (2017) 1105-1121.

52. L. Zuo, B.T. Hemmelgarn, C.C. Chuang, T.M. Best, The role of oxidative stress-induced epigenetic alterations in amyloid- $\beta$ production in Alzheimer's disease, Oxid. Med. Cell. Longev. 2015 (2015) 604658.

53. D.A. Butterfield, D. Boyd-Kimball, Oxidative Stress, Amyloid- $\beta$ Peptide, and Altered Key Molecular Pathways in the Pathogenesis and Progression of Alzheimer's Disease, J. Alzheimer's Dis. 62 (2018) $1345-1367$

54. V. Bonet-Costa, L.C.D. Pomatto, K.J. Davies, The proteasome and oxidative stress in Alzheimer's disease, Antioxid. Redox Signal. 25 (2016) 886-901

55. S. Kar, S.P. Slowikowski, D. Westaway, H.T. Mount, Interactions between $\beta$-amyloid and central cholinergic neurons: implications for Alzheimer's disease, J. Psychiatry Neurosci. 29(2004) 427.

56. E.J. Mufson, S.E. Counts, S.E. Perez, S.D. Ginsberg, Cholinergic system during the progression of Alzheimer's disease: therapeutic implications, Exp. Rev. Neurother, 8 (2008) 1703-1718.

57. J.J. Sutachan, Z. Casas, S.L. Albarracin, B.R. Stab, I. Samudio, J. Gonzalez, L. Morales, G.E. Barreto, Cellular and molecular mechanisms of antioxidants in Parkinson's disease, Nutr. Neurosci. 15 (2012) 120126.

58. P. Vernier, F. Moret, S. Callier, M. Snapyan, C. Wersinger, A. Sidhu, The degeneration of dopamine neurons in Parkinson's disease: insights from embryology and evolution of the mesostriatocortical system, Ann. N. Y. Acad. Sci. 1035(2004) 231-249

59. L.R. Fischer, D.G. Culver, P. Tennant, A.A. Davis, M. Wang, A. Castellano-Sanchez, J. Khan, M.A. Polak, J.D. Glass, Amyotrophic lateral sclerosis is a distal axonopathy: evidence in mice and man, Exp. Neurol. 185 (2004) 232-240

60. J. Jacobsson, P.A. Jonsson, P.M. Andersen, L. Forsgren, S.L. Marklund, Superoxide dismutase in CSF from amyotrophic lateral sclerosis patients with and without $\mathrm{CuZn}$-superoxide dismutase mutations, Brain 124 (2001) 1461-1466. 
61. R.A. Saccon, R.K. Bunton-Stasyshyn, E.M. Fisher, P. Fratta, Is SOD1 loss of function involved in amyotrophic lateral sclerosis? Brain 136 (2013) 2342-2358.

62. G.G. Kovacs, H. Budka, Prion diseases: from protein to cell pathology, Am. J. Pathol. 172 (2008) 555-565.

63. N.J. Cobb, W.K. Surewicz, Prion diseases and their biochemical mechanisms, Biochemistry 48 (2009) 2574.

64. J.A. Simpson, D. Lovecky, J. Kogan, L.A. Vetter, G.J. Yohrling, Survey of the Huntington's disease patient and caregiver community reveals most impactful symptoms and treatment needs, J. Huntington's Dis. 5 (2016) 395-403

65. C.A. Ross, S.J. Tabrizi, Huntington's disease: from molecular pathogenesis to clinical treatment., Lancet Neurol. 10 (2011) 83-98

66. C.Y. Santos, P.J. Snyder, W.C. Wu, M. Zhang, A. Echeverria, J. Alber, Pathophysiologic relationship between Alzheimer's disease, cerebrovascular disease, and cardiovascular risk: A review and synthesis. Alzheimer's Dement. 7(2017) 69-87. doi:10.1016/j.dadm.2017.01.005

67. H.C. Fan, C.S. Chi, S.N. Cheng, H.F. Lee, J.D. Tsai, S.Z. Lin, H.J. Harn, Targeting new candidate genes by small molecules approaching neurodegenerative diseases, Int. J. Mol. Sci. 17 (2016) 26. doi:10.3390/ijms17010026

68. H. Pópulo, J.M. Lopes, P. Soares, The mTOR signalling pathway in human cancer, Int. J. Mol. Sci. 13 (2012) 1886-1918.

69. N. Hay, N. Sonenberg, Upstream and downstream of mTOR. Genes Dev. 18 (2004) 1926-1945.

70. Y.C. Kim, K.L. Guan, mTOR: a pharmacologic target for autophagy regulation, J. Clin. Invest. 125 (2015) $25-32$

71. D.M. Gwinn, D.B. Shackelford, D.F. Egan, M.M. Mihaylova, A. Mery, D.S. Vasquez, B.E. Turk, R.J. Shaw, AMPK phosphorylation of raptor mediates a metabolic checkpoint. Molecular cell 30 (2008) 214226. 
72. G.J. Browne, C.G. Proud, Regulation of peptide-chain elongation in mammalian cells. The FEBS Journal 269 (2002) 5360-5368.

73. M. Cano, A. Ayala, F. Marotta, S. Argüelles, Application of kinase inhibitors for anti-aging intervention, Curr. Pharm. Des. 23(2017) 4351-4368.

74. A. Brunet, J. Park, H. Tran, L.S. Hu, B.A. Hemmings, M.E. Greenberg, Protein kinase SGK mediates survival signals by phosphorylating the forkhead transcription factor FKHRL1 (FOXO3a), Mol. Cell. Biol. 21 (2001) 952-965.

75. N. Mizushima, B. Levine, A.M. Cuervo, D.J. Klionsky, Autophagy fights disease through cellular self-digestion, Nature 451 (2008) 1069-1075.

76. P. Codogno, A. Meijer, Autophagy and signaling: their role in cell survival and cell death. Cell death and differentiation 12 (2005) 1509-1518.

77. W.J. Oh, E. Jacinto, mTOR complex 2 signaling and functions, Cell cycle 10 (2011) 2305-2316

78. I.G. Ganley, d.H. Lam, J. Wang, X. Ding, S. Chen, X. Jiang, ULK1·ATG13. FIP200 complex mediates mTOR signaling and is essential for autophagy, J. Biol. Chem. 284 (2009) 12297-12305

79. N. Hosokawa, T. Sasaki, S.I. Iemura, T. Natsume, T. Hara, N. Mizushima, Atg101, a novel mammalian autophagy protein interacting with Atg13, Autophagy 5 (2009) 973-979

80. N. Hosokawa, T. Hara, T. Kaizuka, C. Kishi, A. Takamura, Y. Miura, S.I. Iemura, T. Natsume, K. Takehana, N. Yamada, Nutrient-dependent mTORC1 association with the ULK1-Atg13-FIP200 complex required for autophagy, Mol. Biol. Cell 20(2009)1981-1991

81. F. Nazio, F. Strappazzon, M. Antonioli, P. Bielli, V. Cianfanelli, M. Bordi, C. Gretzmeier, J. Dengjel, M. Piacentini, G.M. Fimia, mTOR inhibits autophagy by controlling ULK1 ubiquitylation, selfassociation and function through AMBRA1 and TRAF6, Nat. Cell Biol. 15 (2013) 406-416.

82. R.C. Russell, Y. Tian, H. Yuan, H.W. Park, Y.Y. Chang, J. Kim, H. Kim, T.P. Neufeld, A. Dillin, K.L. Guan, ULK1 induces autophagy by phosphorylating Beclin-1 and activating VPS34 lipid kinase, Nat. Cell Biol. 15 (2013) 741-750. 
83. C. Settembre, R. Zoncu, D.L. Medina, F. Vetrini, S. Erdin, S. Erdin, T. Huynh, M. Ferron, G. Karsenty, M.C. Vellard, A lysosome-to-nucleus signalling mechanism senses and regulates the lysosome via mTOR and TFEB, EMBO J. 31 (2012) 1095-1108

84. R. Andrade-Vieira, J.H. Han, P.A. Marignani, Omega-3 polyunsaturated fatty acid promotes the inhibition of glycolytic enzymes and mTOR signaling by regulating the tumor suppressor LKB1, Cancer Biol. Ther. 14(2013) 1050-1058.

85. V. Asati, D.K. Mahapatra, S.K. Bharti, PI3K/Akt/mTOR and Ras/Raf/MEK/ERK signaling pathways inhibitors as anticancer agents: Structural and pharmacological perspectives, Eur. J. Med. Chem. 109(2016) 314-341. doi:10.1016/j.ejmech.2016.01.012

86. S.G. Dann, A. Selvaraj, G. Thomas, mTOR Complex1-S6K1 signaling: at the crossroads of obesity, diabetes and cancer, Trends Mol. Med. 13 (2007) 252-259.

87. I.B. Sahra, C. Regazzetti, G. Robert, K. Laurent, Y. Le Marchand-Brustel, P. Auberger, J.F. Tanti, S. Giorgetti-Peraldi, F. Bost, Metformin, independent of AMPK, induces mTOR inhibition and cell-cycle arrest through REDD1, Cancer Res. 71 (2011) 4366-4372.

88. P. Paschos, K. Paletas, Non alcoholic fatty liver disease and metabolic syndrome, Hippokratia 13 (2009) 9-19

89. B. Levine, G. Kroemer, Autophagy in the pathogenesis of disease, Cell 132 (2008) 27-42. doi:10.1016/j.cell.2007.12.018

90. D.J. Metcalf, M. García-Arencibia, W.E. Hochfeld, D.C. Rubinsztein, Autophagy and misfolded proteins in neurodegeneration, Exp. Neurol. 238 (2012) 22-28.

91. M. Wong, Mammalian target of rapamycin (mTOR) pathways in neurological diseases. Biomedical Journal 36 (2013) 40-50.

92. T. Pan, S. Kondo, W. Le, J. Jankovic, The role of autophagy-lysosome pathway in neurodegeneration associated with Parkinson's disease, Brain 131 (2008) 1969-1978

93. H. Harris, D.C. Rubinsztein, Control of autophagy as a therapy for neurodegenerative disease, Nat. Rev. Neurol. 8(2012) 108-117. 
94. R.L. Vidal, S. Matus, L. Bargsted, C. Hetz, Targeting autophagy in neurodegenerative diseases, Trends Pharmacol. Sci. 35 (2014) 583-591

95. F.M. Menzies, A. Fleming, D.C. Rubinsztein, Compromised autophagy and neurodegenerative diseases, Nat. Rev. Neurosci. 16 (2015) 345-357

96. L.H. Zeng, L. Xu, D.H. Gutmann, M. Wong, Rapamycin prevents epilepsy in a mouse model of tuberous sclerosis complex, Ann. Neurol. 63 (2008) 444-453.

97. R.G. Parsons, G.M. Gafford, F.J. Helmstetter, Translational control via the mammalian target of rapamycin pathway is critical for the formation and stability of long-term fear memory in amygdala neurons, J. Neurosci. 26 (2006) 12977-12983

98. H.Y. Kim, M. Akbar, A. Lau, L. Edsall, Inhibition of neuronal apoptosis by docosahexaenoic acid (22: 6n-3) role of phosphatidylserine in antiapoptotic effect, J. Biol. Chem. 275 (2000) 35215-35223

99. D.H. Kim, D.D. Sarbassov, S.M. Ali, R.R. Latek, K.V. Guntur, H. Erdjument-Bromage, P. Tempst, D.M. Sabatini, GßL, a positive regulator of the rapamycin-sensitive pathway required for the nutrientsensitive interaction between raptor and Mtor, Mol. Cell 11 (2003) 895-904.

100. G.S. Bloom, Amyloid- $\beta$ and tau: the trigger and bullet in Alzheimer disease pathogenesis, JAMA Neurol. 71 (2014) 505-508.

101. R.M. Nisbet, J.C. Polanco, L.M. Ittner, J. Götz, Tau aggregation and its interplay with amyloid- $\beta$, Acta Neuropathol. 129 (2015) 207-220. doi:10.1007/s00401-014-1371-2

102. L. Li, S. Zhang, X. Zhang, T. Li, Y. Tang, H. Liu, W. Yang, W. Le, Autophagy enhancer carbamazepine alleviates memory deficits and cerebral amyloid- $\beta$ pathology in a mouse model of Alzheimer's disease, Curr. Alzheimer Res. 10 (2013) 433-441

103. S.M. Son, H. Song, J. Byun, K.S. Park, H.C. Jang, Y.J. Park, I. Mook-Jung, Altered APP processing in insulin-resistant conditions is mediated by autophagosome accumulation via the inhibition of mammalian target of rapamycin pathway, Diabetes 61 (2012) 3126-3138 
104. C. Lafay-Chebassier, M. Paccalin, G. Page, S. Barc-Pain, M.C. Perault-Pochat, R. Gil, L. Pradier, J. Hugon, mTOR/p70S6k signalling alteration by A $\beta$ exposure as well as in APP-PS1 transgenic models and in patients with Alzheimer's disease, J. Neurochem. 94 (2005) 215-225

105. B. Boland, A. Kumar, S. Lee, F.M. Platt, J. Wegiel, W.H. Yu, A.R. Nixon, Autophagy induction and autophagosome clearance in neurons: relationship to autophagic pathology in Alzheimer's disease, J. Neurosci. 28 (2008) 6926-6937

106. Z. Cai, G. Chen, W. He, M. Xiao, L.J. Yan, Activation of mTOR: a culprit of Alzheimer's disease? Neuropsychiatr. Dis. Treat. 11(2015)1015.

107. P. Spilman, N. Podlutskaya, M.J. Hart, J. Debnath, O. Gorostiza, D. Bredesen, A. Richardson, R. Strong, V. Galvan, Inhibition of mTOR by rapamycin abolishes cognitive deficits and reduces amyloid- $\beta$ levels in a mouse model of Alzheimer's disease, PloS one 5 (2010) e9979

108. P.H. Reddy, M.F. Beal, Amyloid beta, mitochondrial dysfunction and synaptic damage: implications for cognitive decline in aging and Alzheimer's disease, Trends Mol. Med 14(2008) 45-53.

109. R. Franco, E. Martínez-Pinilla, G. Navarro, M. Zamarbide, Potential of GPCRs to modulate MAPK and mTOR pathways in Alzheimer's disease, Prog. Neurobiol. 149(2017) 21-38.

110. D.J. Selkoe, Alzheimer's disease is a synaptic failure, Science 298 (2002) 789-791.

111. T.N. Iwata, J.A. Ramírez-Komo, H. Park, B.M. Iritani, Control of B lymphocyte development and functions by the mTOR signaling pathways, Cytokine Growth Factor Rev. 35(2017) 47-62.

112. V. Galvan, M.J. Hart, Vascular mTOR-dependent mechanisms linking the control of aging to Alzheimer's disease. Biochim. Biophysic. Acta (BBA) - Molecular Basis of Disease 1862 (2016) (5):9921007.

113. T. Ma, C.A. Hoeffer, E. Capetillo-Zarate, F. Yu, H. Wong, M.T. Lin, D. Tampellini, E. Klann, R.D. Blitzer, G.K. Gouras, Dysregulation of the mTOR pathway mediates impairment of synaptic plasticity in a mouse model of Alzheimer's disease, PLoS ONE 5 (2010) e12845.

114. C. Evangelisti, A.M. Martelli, The PI3K/Akt/mTOR Pathway. In: Encyclopedia of Cell Biology. Academic Press, Waltham, 2016, 128-135. 
115. S. Majumder, A. Richardson, R. Strong, S. Oddo, Inducing autophagy by rapamycin before, but not after, the formation of plaques and tangles ameliorates cognitive deficits, PloS one 6, 2011, e25416 116. A. Pierce, N. Podlutskaya, J.J. Halloran, S.A. Hussong, P.Y. Lin, R. Burbank, M.J. Hart, V. Galvan, Over-expression of heat shock factor 1 phenocopies the effect of chronic inhibition of TOR by rapamycin and is sufficient to ameliorate Alzheimer's-like deficits in mice modeling the disease, J. Neurochem. 124 (2013) 880-893

117. Z. Tang, E. Ioja, E. Bereczki, K. Hultenby, C. Li, Z. Guan, B. Winblad, J.J. Pei, mTor mediates tau localization and secretion: Implication for Alzheimer's disease, Biochim. Biophysic. Acta (BBA)-Mol. Cell Res. 1853 (2015) 1646-1657

118. A. Caccamo, A. Magrì, D.X. Medina, E.V. Wisely, M.F. López-Aranda, A.J. Silva, S. Oddo, mTOR regulates tau phosphorylation and degradation: implications for Alzheimer's disease and other tauopathies, Aging Cell 12 (2013) 370-380

119. Y. Liu, Y. Su, J. Wang, S. Sun, T. Wang, X. Qiao, X. Run, H. Li, Z. Liang, Rapamycin decreases tau phosphorylation at Ser214 through regulation of cAMP-dependent kinase, Neurochem. Int. 62 (2013) $458-467$

120. A. Caccamo, S. Majumder, A. Richardson, R. Strong, S. Oddo, Molecular interplay between mammalian target of rapamycin (mTOR), amyloid- $\beta$, and tau effects on cognitive impairments, J. Biol. Chem. 285(2010) 13107-13120

121. G.V. Massey, A. Zipursky, M.N. Chang, J.J. Doyle, S. Nasim, J.W. Taub, Y. Ravindranath, G. Dahl, H.J. Weinstein, A prospective study of the natural history of transient leukemia (TL) in neonates with Down syndrome (DS): Children9s Oncology Group (COG) study POG-9481, Blood 107 (2006) 46064613.

122. L. Nadel, Down's syndrome: a genetic disorder in biobehavioral perspective, Genes Brain Behav. 2(2003), 156-166. 
123. V. Infantino, A. Castegna, F. Iacobazzi, I. Spera, I. Scala, G. Andria, V. Iacobazzi, Impairment of methyl cycle affects mitochondrial methyl availability and glutathione level in Down's syndrome, Mol. Genet. Metab. 102 (2011) 378-382.

124. H.E. Lu, Y.C. Yang, S.M. Chen, H.L. Su, P.C. Huang, M.S. Tsai, T.H. Wang, C.P. Tseng, S.M. Hwang, Modeling neurogenesis impairment in Down syndrome with induced pluripotent stem cells from Trisomy 21 amniotic fluid cells, Exp. Cell Res. 319 (2013) 498-505.

125. J. Busciglio, B.A. Yankner, Apoptosis and increased generation of reactive oxygen species in Down's syndrome neurons in vitro, Nature 378 (1995) 776-779.

126. F. Di Domenico, R. Coccia, A. Cocciolo, M.P. Murphy, G. Cenini, E. Head, D.A. Butterfield, A. Giorgi, M.E. Schinina, C. Mancuso, Impairment of proteostasis network in Down syndrome prior to the development of Alzheimer's disease neuropathology: redox proteomics analysis of human brain, Biochim. Biophysic. Acta (BBA)-Molecular Basis of Disease 1832 (2013) 1249-1259.

127. M. Perluigi, F. Di Domenico, D.A. Butterfield, mTOR signaling in aging and neurodegeneration: At the crossroad between metabolism dysfunction and impairment of autophagy, Neurobiol. Dis. 84(2015) 39-49.

128. F. Di Domenico, A. Tramutola, C. Foppoli, E. Head, M. Perluigi, D.A. Butterfield, mTOR in Down syndrome: Role in $A ß$ and tau neuropathology and transition to Alzheimer disease-like dementia, Free Radic. Biol. Med. 114(2018) 94-101.

129. R.E. Burke, K. O'malley, Axon degeneration in Parkinson's disease, Exp. Neurol. 246(2013) 72-83.

130. B. Pérez-Revuelta, M. Hettich, A. Ciociaro, C. Rotermund, P. Kahle, S. Krauss, D. Di Monte, Metformin lowers Ser-129 phosphorylated $\alpha$-synuclein levels via mTOR-dependent protein phosphatase 2A activation, Cell Death Dis. 5 (2014) e1209.

131. C. Malagelada, Z.H. Jin, V. Jackson-Lewis, S. Przedborski, L.A. Greene, Rapamycin protects against neuron Death in in vitro and in vivo models of Parkinson's disease, J. Neurosci. 30(2010) 11661175. 
132. H. Rekaik, F.X. Blaudin de Thé, A. Prochiantz, J. Fuchs, R.L. Joshi, Dissecting the role of Engrailed in adult dopaminergic neurons - Insights into Parkinson disease pathogenesis, FEBS Lett. 589 (2015) 3786-3794.

133. S. Giacoppo, P. Bramanti, E. Mazzon, Triggering of inflammasome by impaired autophagy in response to acute experimental Parkinson's disease: involvement of the PI3K/Akt/mTOR pathway, Neuroreport 28 (2017) 996-1007. doi:10.1097/wnr.0000000000000871

134. K. Khwanraj, S. Madlah, K. Grataitong, P. Dharmasaroja, Comparative mRNA expression of eEF1A isoforms and a PI3K/Akt/mTOR pathway in a cellular model of Parkinson's disease, Parkinsons Dis. 2016(2016)8716016.

135. A.P. Lan, J. Chen, Y. Zhao, Z. Chai, Y. Hu, mTOR signaling in Parkinson's disease, Neuromol. Med. 19 (2017) 1-10.

136. K. Nakaso, S. Ito, K. Nakashima, Caffeine activates the PI3K/Akt pathway and prevents apoptotic cell death in a Parkinson's disease model of SH-SY5Y cells, Neurosci. Lett. 432 (2008)146-150

137. S.M. Yakhine-Diop, J.M. Bravo-San Pedro, R. Gómez-Sánchez, E. Pizarro-Estrella, M. RodríguezArribas, V. Climent, A. Aiastui, A.L. de Munain, J.M. Fuentes, R.A. González-Polo, G2019S LRRK2 mutant fibroblasts from Parkinson's disease patients show increased sensitivity to neurotoxin 1-methyl-4phenylpyridinium dependent of autophagy. Toxicology 324 (2014)1-9

138. Y. Kitagishi, M. Kobayashi, K. Kikuta, S. Matsuda, Roles of PI3K/AKT/GSK3/mTOR pathway in cell signaling of mental illnesses. Depress. Res. Treat. 2012 (2012) 752563.

139. D. Heras-Sandoval, J.M. Pérez-Rojas, J. Hernández-Damián, J. Pedraza-Chaverri, The role of $\mathrm{PI} 3 \mathrm{~K} / \mathrm{AKT} / \mathrm{mTOR}$ pathway in the modulation of autophagy and the clearance of protein aggregates in neurodegeneration, Cell. Signal. 26 (2014) 2694-2701

140. Q. Zhou, C. Liu, W. Liu, H. Zhang, R. Zhang, J. Liu, J. Zhang, C. Xu, L. Liu, S. Huang, Rotenone induction of hydrogen peroxide inhibits mTOR-mediated S6K1 and 4E-BP1/eIF4E pathways, leading to neuronal apoptosis, Toxicol. Sci. 143 (2014) 81-96. 
141. H. Gao, W. Yang, Z. Qi, L. Lu, C. Duan, C. Zhao, H. Yang, DJ-1 protects dopaminergic neurons against rotenone-induced apoptosis by enhancing ERK-dependent mitophagy, J. Mol. Biol. 423 (2012) $232-248$.

142. F. Wu, H.D. Xu, J.J. Guan, Y.S. Hou, J.H. Gu, X.C. Zhen, Z.H. Qin, Rotenone impairs autophagic flux and lysosomal functions in Parkinson's disease, Neuroscience 284(2015) 900-911.

143. A. Francois, J. Verite, A.R. Bilan, T. Janet, F. Calon, B. Fauconneau, M. Paccalin, G. Page, Chapter 6 - The mTOR Signaling Pathway in Neurodegenerative Diseases A2 - Maiese, Kenneth. In: Molecules to Medicine with mTOR. Academic Press, Boston, 2016, pp 85-104. doi:https://doi.org/10.1016/B978-0$12-802733-2.00011-6$

144. S.Y. Kang, S.B. Lee, H.J. Kim, H.T. Kim, H.O. Yang, W. Jang, Autophagic modulation by rosuvastatin prevents rotenone-induced neurotoxicity in an in vitro model of Parkinson's disease, Neurosci. Lett. 642 (2017) 20-26.

145. Y. Xu, C. Liu, S. Chen, Y. Ye, M. Guo, Q. Ren, L. Liu, H. Zhang, C. Xu, Q. Zhou, Activation of AMPK and inactivation of Akt result in suppression of mTOR-mediated S6K1 and 4E-BP1 pathways leading to neuronal cell death in in vitro models of Parkinson's disease, Cell. Signal. 26 (2014) 16801689.

146. Z. Zhang, G. Li, S.S. Szeto, C.M. Chong, Q. Quan, C. Huang, W. Cui, B. Guo, Y. Wang, Y. Han, Examining the neuroprotective effects of protocatechuic acid and chrysin on in vitro and in vivo models of Parkinson disease, Free Radic. Biol. Med. 84(2015)331-343.

147. B. Ravikumar, C. Vacher, Z. Berger, J.E. Davies, S. Luo, L.G. Oroz, F. Scaravilli, D.F. Easton, R. Duden, C.J. O'Kane, Inhibition of mTOR induces autophagy and reduces toxicity of polyglutamine expansions in fly and mouse models of Huntington disease, Nat. Genet. 36 (2004) 585-595.

148. P. Pasinelli, R.H. Brown, Molecular biology of amyotrophic lateral sclerosis: insights from genetics, Nat. Rev. Neurosci. 7 (2006) 710-723. 
149. A. Bhattacharya, A. Bokov, F.L. Muller, A.L. Jernigan, K. Maslin, V. Diaz, A. Richardson, H. Van Remmen, Dietary restriction but not rapamycin extends disease onset and survival of the H46R/H48Q mouse model of ALS, Neurobiol. Aging 33 (2012) 1829-1832

150. X. Zhang, L. Li, S. Chen, D. Yang, Y. Wang, X. Zhang, Z. Wang, W. Le, Rapamycin treatment augments motor neuron degeneration in SOD1G93A mouse model of amyotrophic lateral sclerosis, Autophagy 7 (2011) 412-425

151. J.K. Ching, C.C. Weihl, Rapamycin-induced autophagy aggravates pathology and weakness in a mouse model of VCP-associated myopathy, Autophagy 9 (2013) 799-800

152. X. Zhang, S. Chen, L. Song, Y. Tang, Y. Shen, L. Jia, W. Le, MTOR-independent, autophagic enhancer trehalose prolongs motor neuron survival and ameliorates the autophagic flux defect in a mouse model of amyotrophic lateral sclerosis, Autophagy 10 (2014) 588-602

153. R. Aleksis, F. Oleskovs, K. Jaudzems, J. Pahnke, H. Biverstål, Structural studies of amyloid- $\beta$ peptides: Unlocking the mechanism of aggregation and the associated toxicity. Biochimie 140 (2017) 176-192.

154. D.J. Selkoe, The deposition of amyloid proteins in the aging mammalian brain: implications for Alzheimer's disease, Ann. Med. 21 (1989) 73-76.

155. R. Rathod, A. Kale, S. Joshi, Novel insights into the effect of vitamin B 12 and omega-3 fatty acids on brain function, J. Biomed. Sci. 23 (2016) 17.

156. M.H. Bloch, A. Qawasmi, Omega-3 fatty acid supplementation for the treatment of children with attention-deficit/hyperactivity disorder symptomatology: systematic review and meta-analysis, J. Am. Acad. Child Adolesc. Psychiatry 50 (2011) 991-1000.

157. E. Hjorth, M. Zhu, V.C. Toro, I. Vedin, J. Palmblad, T. Cederholm, Y. Freund-Levi, G. FaxenIrving, L.O. Wahlund, H. Basun, Omega-3 fatty acids enhance phagocytosis of Alzheimer's diseaserelated amyloid- $\beta 42$ by human microglia and decrease inflammatory markers, J. Alzheimer's Dis. 35 (2013) 697-713. 
158. R. Dang, X. Zhou, P. Xu, Y. Guo, X. Gong, S. Wang, F. Yuan, J. Yao, P. Jiang, $\omega-3$ polyunsaturated fatty acid supplementation ameliorates lipopolysaccharide-induced behavioral deficits and modulates neurotrophic factors in rats: Focus on tPA/PAI-1 system and BDNF-TrkB signaling, J. Funct. Foods 30 (2017) 74-80.

159. J.E. Choi, Y. Park, EPA and DHA, but not ALA, have antidepressant effects with 17ß-estradiol injection via regulation of a neurobiological system in ovariectomized rats, J. Nutr. Biochem. 49 (2017) 101-109.

160. Y. Freund-Levi, I. Vedin, E. Hjorth, H. Basun, G. Faxén Irving, M. Schultzberg, M. Eriksdotter, J. Palmblad, B. Vessby, L.O. Wahlund, Effects of supplementation with omega-3 fatty acids on oxidative stress and inflammation in patients with Alzheimer's disease: the OmegAD study, J. Alzheimer's Dis. 42 (2014) 823-831.

161. M. Eriksdotter, I. Vedin, F. Falahati, Y. Freund-Levi, E. Hjorth, G. Faxen-Irving, L.O. Wahlund, M. Schultzberg, H. Basun, T. Cederholm, Plasma fatty acid profiles in relation to cognition and gender in Alzheimer's disease patients during oral omega-3 fatty acid supplementation: The omegad study, J. Alzheimer's Dis. 48 (2015) 805-812.

162. F. Calon, G. Cole, Neuroprotective action of omega-3 polyunsaturated fatty acids against neurodegenerative diseases: evidence from animal studies, Prostaglandins Leukot. Essent. Fatty Acids 77 (2007) $287-293$

163. E. Masliah, L. Crews, L. Hansen, Synaptic remodeling during aging and in Alzheimer's disease, J. Alzheimer's Dis. 9 (2006):91-99

164. G.P. Lim, F. Calon, T. Morihara, F. Yang, B. Teter, O. Ubeda, N. Salem, S.A. Frautschy, G.M. Cole A diet enriched with the omega-3 fatty acid docosahexaenoic acid reduces amyloid burden in an aged Alzheimer mouse model, J. Neurosci. 25 (2005) 3032-3040

165. M. Oksman, H. Iivonen, E. Hogyes, Z. Amtul, B. Penke, I. Leenders, L. Broersen, D. Lütjohann, T. Hartmann, H. Tanila, Impact of different saturated fatty acid, polyunsaturated fatty acid and cholesterol 
containing diets on beta-amyloid accumulation in APP/PS1 transgenic mice, Neurobiol. Dis. 23 (2006) 563-572.

166. K.N. Green, H. Martinez-Coria, H. Khashwji, E.B. Hall, K.A. Yurko-Mauro, L. Ellis, F.M. LaFerla, Dietary docosahexaenoic acid and docosapentaenoic acid ameliorate amyloid- $\beta$ and tau pathology via a mechanism involving presenilin 1 levels, J. Neurosci. 27 (2007) 4385-4395

167. J. Xu, S. Chen, S.H. Ahmed, H. Chen, G. Ku, M.P. Goldberg, C.Y. Hsu, Amyloid- $\beta$ peptides are cytotoxic to oligodendrocytes, J. Neurosci. 21 (2001):RC118-RC118

168. Y. Zhang, R. McLaughlin, C. Goodyer, A. LeBlanc, Selective cytotoxicity of intracellular amyloid $\beta$ peptide1-42 through p53 and Bax in cultured primary human neurons, J. Cell Biol. 156 (2002) 519-529.

169. K. Kusat Ol, G. Kanbak, A. Oğlakcı Ilhan, D. Burukoglu, F. Yücel, The investigation of the prenatal and postnatal alcohol exposure-induced neurodegeneration in rat brain: protection by betaine and/or omega-3. Child's Nervous System 32 (2016) 467-474.

170. H. Jedema, M. Carter, B. Dugan, K. Gurnsey, A. Olsen, C. Bradberry, The acute impact of ethanol on cognitive performance in rhesus macaques, Cereb Cortex 21 (2011) 1783-1791.

171. A. Paintner, A. Williams, L. Burd, Fetal alcohol spectrum disorders-implications for child neurology, part 2: diagnosis and management, J. Childern Neurol. 27 (2012) 355-362.

172. C. Ikonomidou, P. Bittigau, M.J. Ishimaru, D.F. Wozniak, C. Koch, K. Genz, M.T. Price, V. Stefovska, F. Hörster, T. Tenkova, Ethanol-induced apoptotic neurodegeneration and fetal alcohol syndrome, Science 287 (2000) 1056-1060.

173. F.J. Northington, R. Chavez-Valdez, L.J. Martin, Neuronal cell death in neonatal hypoxia-ischemia, Ann. Neurol. 69 (2011) 743-758.

174. F.A. Fakoya, E.A. Caxton-Martins, Neocortical neurodegeneration in young adult Wistar rats prenatally exposed to ethanol, Neurotoxicol. Teratol. 28 (2006) 229-237.

175. B. Heude, P. Ducimetière, C. Berr, Cognitive decline and fatty acid composition of erythrocyte membranes-The EVA Study, Am. J. Clin. Nutr. 77 (2003) 803-808. 
176. M.C. Morris, D.A. Evans, C.C. Tangney, J.L. Bienias, R.S. Wilson, Fish consumption and cognitive decline with age in a large community study, Arch. Neurol. 62 (2005)1849-1853.

177. B.M. van Gelder, M. Tijhuis, S. Kalmijn, D. Kromhout, Fish consumption, $n-3$ fatty acids, and subsequent 5-y cognitive decline in elderly men: the Zutphen Elderly Study, Am. J. Clin. Nutr. 85 (2007) 1142-1147.

178. O. van de Rest, J.M. Geleijnse, F.J. Kok, W.A. van Staveren, C. Dullemeijer, M.G. OldeRikkert, A.T. Beekman, C. De Groot, Effect of fish oil on cognitive performance in older subjects A randomized, controlled trial, Neurology 71 (2008) 430-438

179. T. Terano, S. Fujishiro, T. Ban, K. Yamamoto, T. Tanaka, Y. Noguchi, Y. Tamura, K. Yazawa, T. Hirayama, Docosahexaenoic acid supplementation improves the moderately severe dementia from thrombotic cerebrovascular diseases, Lipids 34 (1999) S345-S346

180. S. Kotani, E. Sakaguchi, S. Warashina, N. Matsukawa, Y. Ishikura, Y. Kiso, M. Sakakibara, T. Yoshimoto, J. Guo, T. Yamashima, Dietary supplementation of arachidonic and docosahexaenoic acids improves cognitive dysfunction, Neurosci. Res. 56 (2006) 159-164.

181. Y. Freund-Levi, M. Eriksdotter-Jönhagen, T. Cederholm, H. Basun, G. Faxén-Irving, A. Garlind, I. Vedin, B. Vessby, L.O. Wahlund, J. Palmblad, $\omega-3$ fatty acid treatment in 174 patients with mild to moderate Alzheimer disease: OmegAD Study: a randomized double-blind trial, Arch. Neurol. 63 (2006) $1402-1408$.

182. G.P. Eckert, U. Lipka, W.E. Muller, Omega-3 fatty acids in neurodegenerative diseases: focus on mitochondria, Prostaglandins Leukot Essent Fatty Acids 88 (2013) 105-114.

183. C. Garrel, J.M. Alessandri, P. Guesnet, K.H. Al-Gubory, Omega-3 fatty acids enhance mitochondrial superoxide dismutase activity in rat organs during post-natal development, Int. J. Biochem. Cell Biol. 44 (2012) 123-131.

184. D. D'Eliseo, F. Velotti, Omega-3 fatty acids and cancer cell cytotoxicity: Implications for multitargeted cancer therapy, J. Clin. Med. 5 (2016) 15. doi:10.3390/jcm5020015 
185. T. Hatano, S.I. Kubo, S. Sato, N. Hattori, Pathogenesis of familial Parkinson's disease: new insights based on monogenic forms of Parkinson's disease, J. Neurochem. 111 (2009) 1075-1093.

186. R. Obeid, W. Herrmann, Mechanisms of homocysteine neurotoxicity in neurodegenerative diseases with special reference to dementia, FEBS Lett. 580 (2006) 2994-3005.

187. H.Y. Kim, M. Akbar, Y.S. Kim, (2010) Phosphatidylserine-dependent neuroprotective signaling promoted by docosahexaenoic acid, Prostaglandins Leukot. Essent. Fatty Acids 82 (2010) 165-172

188. D.P. Brazil, B.A. Hemmings, Ten years of protein kinase B signalling: a hard Akt to follow, Trends Biochem. Sci. 26 (2001) 657-664.

189. M. Akbar, H.Y. Kim, Protective effects of docosahexaenoic acid in staurosporine-induced apoptosis: Involvement of phosphatidylinositol-3 kinase pathway, J. Neurochem. 82 (2002) 655-665.

190. M. Akbar, F. Calderon, Z. Wen, H.Y. Kim, Docosahexaenoic acid: a positive modulator of Akt signaling in neuronal survival, Proc. Natl. Acad. Sci. USA 102 (2005) 10858-10863

191. D.T. Stark, N.G. Bazan, Neuroprotectin D1 induces neuronal survival and downregulation of amyloidogenic processing in Alzheimer's disease cellular models, Mol. Neurobiol. 43 (2011) 131-138 192. Y. Zhao, F. Calon, C. Julien, J.W. Winkler, N.A. Petasis, W.J. Lukiw, N.G. Bazan, Docosahexaenoic acid-derived neuroprotectin D1 induces neuronal survival via secretase-and PPAR $\gamma$ mediated mechanisms in Alzheimer's disease models, PLoS ONE 6 (2011) e15816

193. N.A. Halapin, N.G. Bazan, NPD1 induction of retinal pigment epithelial cell survival involves PI3K/Akt phosphorylation signaling, Neurochem. Res. 35 (2010) 1944-1947

194. Z. Faghiri, N.G. Bazan, PI3K/Akt and mTOR/p70S6K pathways mediate neuroprotectin D1-induced retinal pigment epithelial cell survival during oxidative stress-induced apoptosis, Exp. Eye Res 90 (2010) $718-725$

195. L.Q. Ma, F. Yang, E.R. Rosario, O.J. Ubeda, W. Beech, D.J. Gant, P.P. Chen, B. Hudspeth, C. Chen , Y. Zhao, $\beta$-amyloid oligomers induce phosphorylation of tau and inactivation of insulin receptor substrate via c-Jun N-terminal kinase signaling: suppression by omega-3 fatty acids and curcumin, J. Neurosci. 29 (2009) 9078-9089 
196. L.H. Jiang, Y. Shi, L.S. Wang, Z.R. Yang, The influence of orally administered docosahexaenoic acid on cognitive ability in aged mice, J. Nutr. Biochem. 20 (2009) 735-741.

197. L. Calza, L. Giardino, A. Giuliani, L. Aloe, R. Levi-Montalcini, (2001) Nerve growth factor control of neuronal expression of angiogenetic and vasoactive factors, Proc. Natl. Acad. Sci. USA 98(2001) 4160-4165.

198. T. Licht, I. Goshen, A. Avital, T. Kreisel, S. Zubedat, R. Eavri, (2011) Reversible modulation of neuronal plasticity by VEGF, Proc. Natl. Acad. Sci. USA 108(2011) 5081-5086.

199. P. Garcia-Maceira, J. Mateo, Silibinin inhibits hypoxia-inducible factor- $1 \alpha$ and mTOR/p70S6K/4EBP1 signalling pathway in human cervical and hepatoma cancer cells: implications for anticancer therapy, Oncogene 28 (2009) 313-324.

200. S. Kim, K. Jing, S. Shin, S. Jeong, S.H. Han, H. Oh, Y.S. Yoo, J. Han, Y.J. Jeon, J.Y. Heo, w3polyunsaturated fatty acids induce cell death through apoptosis and autophagy in glioblastoma cells: In vitro and in vivo, Oncol. Rep. 39 (2018) 239-246

201. N. Kim, S. Jeong, K. Jing, S. Shin, S. Kim, J.Y. Heo, G.R. Kweon, S.K. Park, T. Wu, J.I. Park, (2015) Docosahexaenoic acid induces cell death in human non-small cell lung cancer cells by repressing mTOR via AMPK activation and PI3K/Akt inhibition, Biomed Res. Int. 2015(2015)239764.

202. J. Liu, M. Xu, Y. Zhao, C. Ao, Y. Wu, Z. Chen, B. Wang, X. Bai, M. Li, W. Hu, n-3 polyunsaturated fatty acids abrogate mTORC1/2 signaling and inhibit adrenocortical carcinoma growth in vitro and in vivo, Oncol. Rep. 35 (2016) 3514-3522

203. N. Garay-Lugo, A. Domínguez-Lopez, A. Miliar García, E. Aguilar Barrera, M. Gómez López, A. Gómez Alcalá, MdlA Martínez Godinez, E. Lara-Padilla, n-3 fatty acids modulate the mRNA expression of the Nlrp3 inflammasome and Mtor in the liver of rats fed with high-fat or high-fat/fructose diets, Immunopharmacol. Immunotoxicol. 38 (2016) 353-363

204. M.M. Georgescu, PTEN tumor suppressor network in PI3K-Akt pathway control, Genes Cancer 1 (2010) 1170-1177. 
205. X. Bi, F. Li, S. Liu, Y. Jin, X. Zhang, T. Yang, Y. Dai, X. Li, A.Z. Zhao, $\omega-3$ polyunsaturated fatty acids ameliorate type 1 diabetes and autoimmunity, J. Clin. Investig. 127 (2017)1757-1771.

206. S. Shin, K. Jing, S. Jeong, N. Kim, K.S. Song, J.Y. Heo, J.H. Park, K.S. Seo, J. Han, J.I. Park, The omega-3 polyunsaturated fatty acid DHA induces simultaneous apoptosis and autophagy via mitochondrial ROS-mediated Akt-mTOR signaling in prostate cancer cells expressing mutant p53, BioMed Res. Int. 2013(2013)568671.

207. G.I. Smith, P. Atherton, D.N. Reeds, B.S. Mohammed, D. Rankin, M.J. Rennie, B. Mittendorfer, Dietary omega-3 fatty acid supplementation increases the rate of muscle protein synthesis in older adults: a randomized controlled trial, Am. J. Clin. Nutr. 93 (2011) 402-412.

208. M.A. Phillips, C.E. Childs, P.C. Calder, P.J. Rogers, Lower omega-3 fatty acid intake and status are associated with poorer cognitive function in older age: A comparison of individuals with and without cognitive impairment and Alzheimer's disease, Nutr. Neurosci. 15 (2012) 271-277.

209. R. Calero, E. Morchon, I. Martinez-Argudo, R. Serrano, Synergistic anti-tumor effect of 17AAG with the PI3K/mTOR inhibitor NVP-BEZ235 on human melanoma, Cancer Lett. 406 (2017) 1-11.

210. T. Jiang, J. Du, Raynald, J. Wang, C. Li, Presurgical administration of mTOR Inhibitors in patients with large subependymal giant cell astrocytoma associated with tuberous sclerosis complex. World Neurosurg. 107(2017)1053.e1-1053.e6.

211. T.Y. Forbes-Hernández, F. Giampieri, M. Gasparrini, L. Mazzoni, J.L. Quiles, J.M. Alvarez-Suarez, M. Battino, The effects of bioactive compounds from plant foods on mitochondrial function: A focus on apoptotic mechanisms, Food Chem. Toxicol. 68 (2014) 154-182

212. N.M. Davis, M. Sokolosky, K. Stadelman, S.L. Abrams, M. Libra, S. Candido, F. Nicoletti, J. Polesel, R. Maestro, A. D'Assoro, Deregulation of the EGFR/PI3K/PTEN/Akt/mTORC1 pathway in breast cancer: possibilities for therapeutic intervention, Oncotarget 5 (2014) 4603

213. C.W. Keller, J. Schmidt, J.D. Lünemann, Immune and myodegenerative pathomechanisms in inclusion body myositis, Ann. Clin. Transl. Neurol. 4 (2017) 422-445. 
214. L. Gil del Valle, R. Gravier Hernández, L. Delgado Roche, O.S. León Fernández, Oxidative stress in the aging process: Fundamental aspects and new insights. In: Oxidative Stress: Diagnostics, Prevention, and Therapy Volume 2. ACS Publications, 2015, 177-219.

215. A. Fappi, T.S. Godoy, J.R. Maximino, V.R. Rizzato, J.D.C. Neves, G. Chadi, E. Zanoteli, The effects of omega-3 fatty acid supplementation on dexamethasone-induced muscle atrophy, BioMed Res. Int. 2014(2014):961438.

216. D. Gwon, T. Hwang, J.Y. Ro, Y.J. Kang, J. Jeong, D.K. Kim, K. Lim, D. Kim, D. Choi, J.J. Kim, High Endogenous accumulation of $\omega-3$ polyunsaturated fatty acids protect against ischemia-reperfusion renal injury through AMPK-mediated autophagy in fat-1 mice, Int. J. Mol. Sci. 18 (2017) 2081.

217. R. Roskoski Jr, Guidelines for preparing color figures for everyone including the colorblind, Pharmacol. Res. 119 (2017) 240-241.

D.D. Sarbassov, S.M. Ali, S. Sengupta, J.H. Sheen, P.P. Hsu, A.F. Bagley, Prolonged rapamycin treatment inhibits mTORC2 assembly and Akt/PKB. Molecular Cell 22 (2006)159-168.

218. J.B. Jahrling, R.M. Laberge, (2015 Age-related neurodegeneration prevention through mTOR Inhibition: Potential mechanisms and remaining questions, Curr. Topics Med. Chem. 15 (2015) 21392151.

219. M. Wong, Mammalian Target of Rapamycin (mTOR) Pathways in Neurological Diseases. Biomed. J. 36 (2013)10.4103/2319-4170.110365.

220. Z.Z. Chong, Y.C. Shang, L. Zhang, S. Wang, K. Maiese, Mammalian Target of Rapamycin: Hitting the Bull's-Eye for Neurological Disorders, Oxid. Med. Cell. Longev. 3 (2010) 374-391.

221. M. Markowicz-Piasecka, J. Sikora, A. Szydłowska, A. Skupień, E. Mikiciuk-Olasik, K.M. Huttunen (2017) Metformin-a future therapy for neurodegenerative diseases, Pharm. Res. 34(2017) 2614-2627.

222. Y. Yang, B. Zhu, F. Zheng, Y. Li, Y. Zhang, Y. Hu, X. Wang, Chronic metformin treatment facilitates seizure termination, Biochem. Biophysic. Res. Commun. 484 (2017) 450-455. 
223. C.H. Chen, C.C. Chiu, M.C. Huang, T.H. Wu, H.C. Liu, M.L. Lu, Metformin for metabolic dysregulation in schizophrenic patients treated with olanzapine, Progr. Neuro-Psychopharmacol. Biol. Psychiatr. 32 (2008) 925-931.

224. T.F. Jiang, Y.J. Zhang, H.Y. Zhou, H.M. Wang, L.P. Tian, J. Liu, J.Q. Ding, S.D. Chen, Curcumin Ameliorates the Neurodegenerative Pathology in A53T $\alpha$-synuclein Cell Model of Parkinson's Disease Through the Downregulation of mTOR/p70S6K Signaling and the Recovery of Macroautophagy, J. Neuroimmune Pharmacol. 8(2013) 356-369.

225. X.F. Meng, J.T. Yu, J.H. Song, S. Chi, L. Tan (2013) Role of the mTOR signaling pathway in epilepsy, J. Neurol. Sci. 332 (2013) 4-15.

226. A. Dey, J.N. De, Neuroprotective therapeutics from botanicals and phytochemicals against Huntington's disease and related neurodegenerative disorders, J. Herbal Med. 5 (2015)1-19.

227. K. Wu, X. Gao, B. Shi, S. Chen, X. Zhou, Z. Li, Y. Gan, L. Cui, J.X. Kang, W. Li, R. Huang, Enriched endogenous n-3 polyunsaturated fatty acids alleviate cognitive and behavioral deficits in a mice model of Alzheimer's disease, Neuroscience 333 (2016) 345-355.

228. M. Diaz, N. Fabelo, V. Casañas-Sánchez, R. Marin, T. Gomez, D. Quinto-Alemany, J.A. Pérez, Hippocampal lipid homeostasis in APP/PS1 mice is modulated by a complex interplay between dietary DHA and estrogens: Relevance for Alzheimer's disease, J. Alzheimer's Dis. 49 (2016) 459-481.

229. E. Teng, K. Taylor, T. Bilousova, D. Weiland, T. Pham, X. Zuo, F. Yang, P.P. Chen, C.G. Glabe, A. Takacs, D.R. Hoffman, S.A. Frautschy, G.M. Cole, Dietary DHA supplementation in an APP/PS1 transgenic rat model of $\mathrm{AD}$ reduces behavioral and $\mathrm{A} \beta$ pathology and modulates $\mathrm{A} \beta$ oligomerization, Neurobiol. Dis. 82 (2015) 552-560.

230. H.M. Olivera-Perez, L. Lam, J. Dang, W. Jiang, F. Rodriguez, E. Rigali, S. Weitzman, V. Porter, L. Rubbi, M. Morselli, (2017) Omega-3 fatty acids increase the unfolded protein response and improve amyloid- $\beta$ phagocytosis by macrophages of patients with mild cognitive impairment, FASEB J. 31 (2017) 4359-4369. 
231. S. Shashikumar, H. Pradeep, S. Chinnu, P.S. Rajini, G.K. Rajanikant, Alpha-linolenic acid suppresses dopaminergic neurodegeneration induced by 6-OHDA in C. elegans, Physiol. Behav. 151 (2015)563-569.

232. T. Pawełczyk, E. Piątkowska-Janko, P. Bogorodzki, P. Gębski, M. Grancow-Grabka, E. Trafalska, N. Żurner, A. Pawełczyk, (2017) Omega-3 fatty acid supplementation may prevent loss of gray matter thickness in the left parieto-occipital cortex in first episode schizophrenia: A secondary outcome analysis of the OFFER randomized controlled study, Schizophr Res. 195 (2018)168-175.

233. M. Manes, A. Alberici, E. Di Gregorio, L. Boccone, E. Premi, N. Mitro, M.P. Pasolini, C. Pani, B. Paghera, D. Perani, Docosahexaenoic acid (DHA) is a beneficial replacement treatment for Spinocerebellar Ataxia 38 (SCA38), Ann. Neurol. 82(2017)615-621.

234. P. Mancera, B. Wappenhans, B. Cordobilla, N. Virgili, M. Pugliese, F. Rueda, J.F. Espinosa-Parrilla, J.C. Domingo, Natural docosahexaenoic acid in the triglyceride form attenuates in vitro microglial activation and ameliorates autoimmune encephalomyelitis in mice, Nutrients 9 (2017) 681.

235. A.I. Ostermann, M. Reutzel, N. Hartung, N. Franke, L. Kutzner, K. Schoenfeld, K.H. Weylandt, G.P. Eckert, N.H. Schebb (2017) A diet rich in omega-3 fatty acids enhances expression of soluble epoxide hydrolase in murine brain, Prostaglandins Other Lipid Mediat.133 (2017)79-87.

236. H.N. Yassine, V. Rawat, W.J. Mack, J.F. Quinn, K. Yurko-Mauro, E. Bailey-Hall, P.S. Aisen, H.C. Chui, L.S. Schneider, The effect of APOE genotype on the delivery of DHA to cerebrospinal fluid in Alzheimer's disease. Alzheimer's Res. Ther. 8(2016) 25.

237. J.J. Ferreira, A. Rosser, D. Craufurd, F. Squitieri, N. Mallard, B. Landwehrmeyer, Ethyl-eicosapentaenoic acid treatment in Huntington's disease: A placebo-controlled clinical trial, Mov. Dis. 30 (2015)1426-1429.

238. X. Wang, E. Hjorth, I. Vedin, M. Eriksdotter, Y. Freund-Levi, L.O. Wahlund, T. Cederholm, J. Palmblad, M. Schultzberg, Effects of n-3 FA supplementation on the release of proresolving lipid mediators by blood mononuclear cells: the OmegAD study, J. Lipid Res. 56 (2015) 674-681. 
239. O. Rikkert, G. Marcel, F.R. Verhey, R. Blesa, C.A. von Arnim, A. Bongers, J. Harrison, J. Sijben, E. Scarpini, M.F. Vandewoude, Tolerability and safety of Souvenaid in patients with mild Alzheimer's disease: results of multi-center, 24-week, open-label extension study, J. Alzheimer's Dis. 44 (2015) 471480.

240. M. Pardini, C. Serrati, S. Guida, C. Mattei, L. Abate, D. Massucco, D. Sassos, M. Amore, F. Krueger, L. Cocito, Souvenaid reduces behavioral deficits and improves social cognition skills in frontotemporal dementia: a proof-of-concept study, Neurodegener. Dis.15 (2015) 58-62.

241. S. Smesny, B. Milleit, M.R. Schaefer, J. Hesse, M. Schlögelhofer, K. Langbein, U.C. Hipler, M. Berger, D.R. Cotter, H. Sauer, P.D. McGorry, G.P. Amminger, Effects of omega-3 PUFA on immune markers in adolescent individuals at ultra-high risk for psychosis - Results of the randomized controlled Vienna omega-3 study, Schizophr. Res. 188 (2017)110-117. 
Figures legends:

Figure 1. Structures of some common Omega-3 PUFAs<smiles>CCC=CCC=CCC=CCCCCCCCC(=O)O</smiles>

$\alpha$ Linolenic acid (ALA)

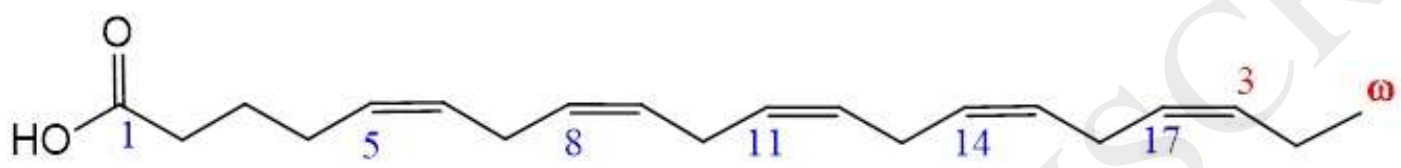

Eicosapentaenoic acid (EPA)

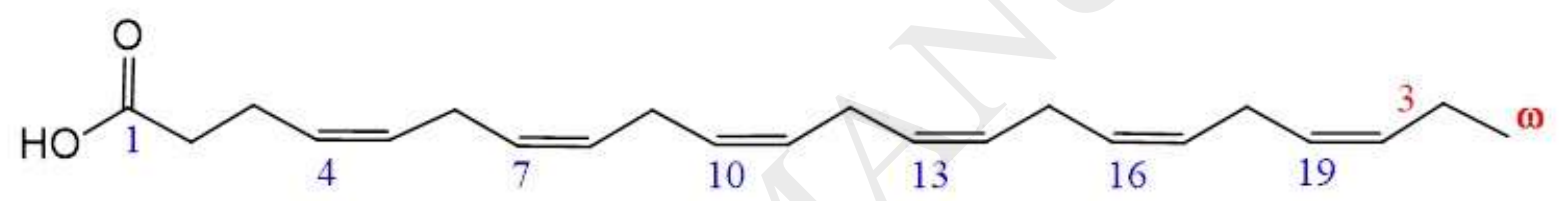

Docosahexaenoic acid (DHA)

Figure 2: Role and regulation of mTOR signaling pathway. mTOR is a major modulator of autophagy and it receives inputs from different signaling pathways. The kinase mTOR is a downstream target of PI3K and kinase AKT pathway, which is activated by receptors of neurotrophins and growth factors, and promotes cell growth, differentiation and survival, while downregulating apoptotic signals. AKT also promotes mTOR activity by suppressing the repressive action of TSC by phosphorylating TSC2. TSC 2 phosphorylation promotes activation of Rheb and stimulation of mTOR activity. Rag A/B is also activated by the presence of RagGTPase, which further regulates mTOR signaling. Activation of mTOR leads to regulation of many target proteins including FoxO3, $\mathrm{A} \beta$, autophagy, synaptic plasticity, cell growth, 
differentiation and survival. This figure has been prepared according to the guidelines as published in [217].

mTOR (mammalian target of rapamycin), PI3K (phosphatidylinositol 3 kinase), TSC (tuberous sclerosis complex), Rheb (Ras homolog enriched in brain), Rag (recombination activating gene), A $\beta$ (amyloid beta), ATG (autophagy related protein), ULK (serine/threonine protein kinase ULK), FoxO3 (forkhead box O3)

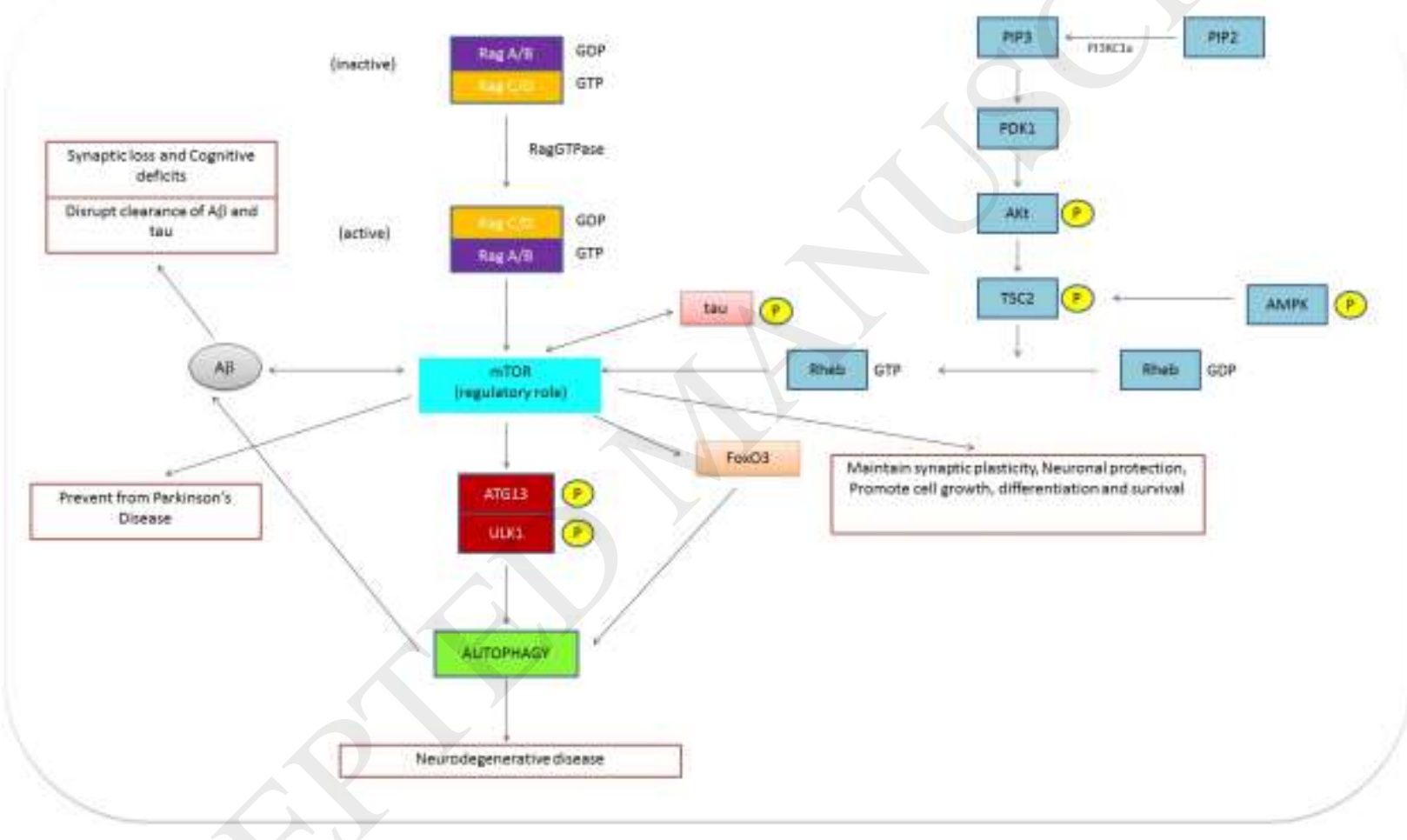

Figure 3. Potential of omega-3 in neurodegenerative diseases therapy through inhibition of mammalian target of rapamycin (mTOR) signaling pathway. Aging, stress and inflammation are common risk factor for neurodegenerative diseases such as Alzheimer's (AD), Parkinson's (PD), amyotrophic lateral sclerosis (ALS), and Huntington's disease (HD), in which defects in autophagy cause accumulation of toxic proteins in neurons which leads to neural damage and death. The mTOR has a key role in important cellular process such as cell survival, protein synthesis, mitochondrial biogenesis, proliferation, apoptosis, and is negative regulator of 
autophagy. The mTOR signaling can be activated by PI3K/AKT and inhibited by AMPK. Omega-3 can inhibits mTOR activity through a mechanism involving activation of PTEN and AMPK. Eicosapentaenoic acid (EPA), docosahexaenoic acid (DHA) and $\alpha$-Linolenic acid (ALA), adenosine monophosphate-activated protein kinase (AMPK), tuberous sclerosis complex (TSC), ribosomal protein S6 kinase (S6K), initiation factor 4E-binding protein (4E-BP), eukaryotic initiation factor 4E (eIF4E), eukaryotic initiation factor 4B (eIF4B).

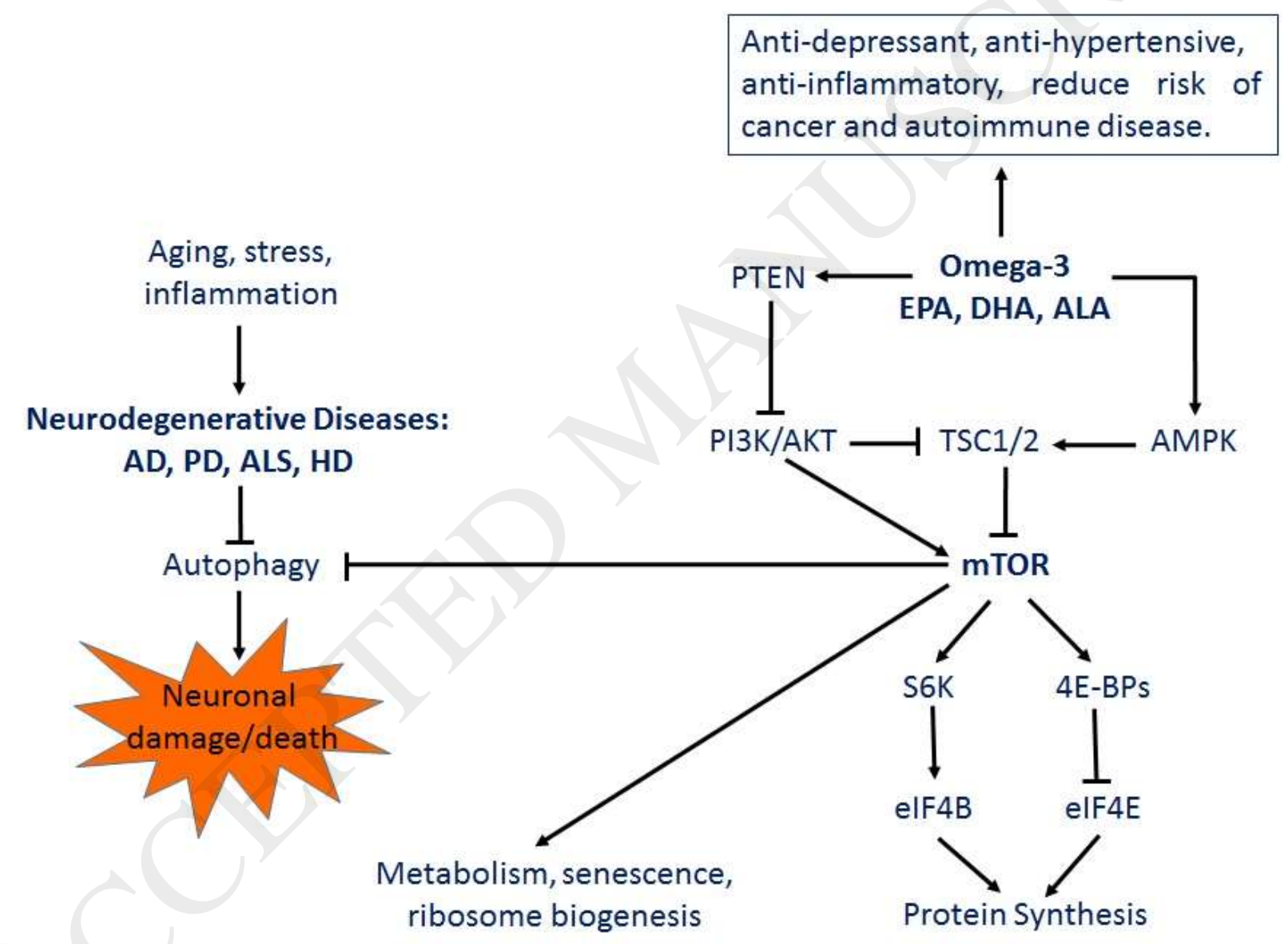

Figure 4. Schematic report on literature evidence suggesting omega-3 as mTOR inhibitor in neurodegenerative diseases. Omega-3 PUFAs which are recognized as mTOR inhibitors in different chronic pathologies, might be also considered as mTOR inhibitory agents to develop 
new therapeutic

strategies

for

NDs.

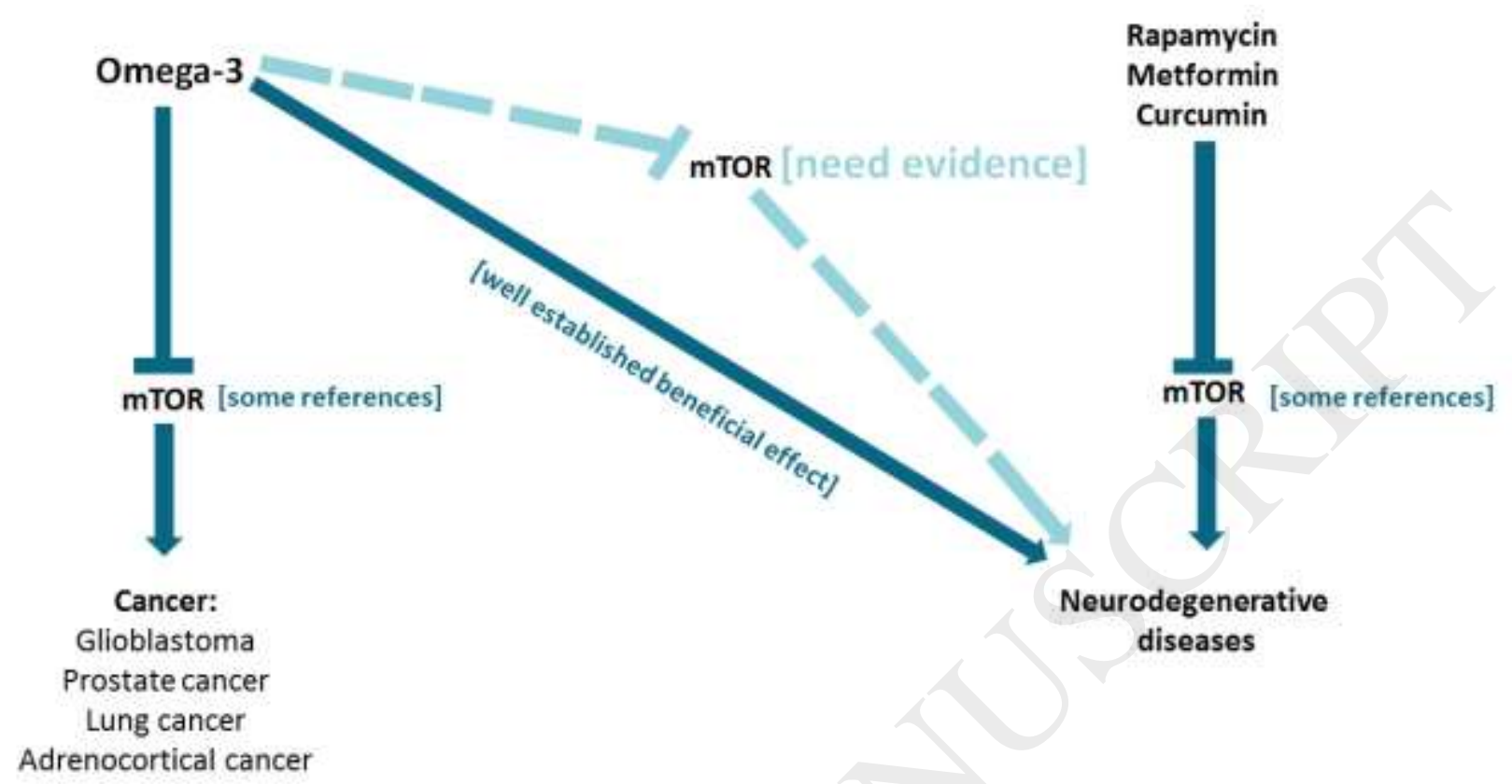




\section{Table}

Table 1. mTOR inhibitors used in the context of neurodegenerative diseases.

\begin{tabular}{|l|l|l|}
\hline Compounds & Type of NDs & Reference \\
\hline Rapamycin & Seizures, tuberous sclerosis & {$[218,108,219-221]$} \\
complex, Alzheimer disease, & Parkinson disease and & \\
& Huntington disease, & \\
& neurofibromatosis, fragile X & \\
& syndrome, epilepsy, traumatic & \\
\hline Metformin & brain injury Huntington & {$[225-227]$} \\
\hline Curcumin & Seizure, schizophrenia & {$[222-224]$} \\
& PD, epilepsy, Hisease & \\
\hline
\end{tabular}


Table 2. Omega-3 treatment effects on neurodegenerative diseases models

\begin{tabular}{|c|c|c|c|}
\hline Omega-3 & Type of NDs & Effect & Reference \\
\hline n-3 PUFAs & $\mathrm{AD}$ & $\begin{array}{l}\text { Slow down cognitive decline and } \\
\text { prevent neuropsychological disorder in } \\
\text { AD }\end{array}$ & {$[228]$} \\
\hline DHA & $\mathrm{AD}$ & $\begin{array}{l}\text { Modulate hippocampal lipid } \\
\text { homeostasis }\end{array}$ & [229] \\
\hline DHA & $\mathrm{AD}$ & $\begin{array}{l}\text { Reduce the formation of both } A \beta \\
\text { plaques and prefibrillar } A \beta \text { oligomers }\end{array}$ & [230] \\
\hline $\begin{array}{l}\text { Omega-3 fatty } \\
\text { acids }\end{array}$ & $\mathrm{AD}$ & $\begin{array}{l}\text { increase the unfolded protein response } \\
\text { and improve amyloid- } \beta \text { phagocytosis by } \\
\text { macrophages }\end{array}$ & [231] \\
\hline$\alpha$-linolenic acid & PD & $\begin{array}{l}\text { Suppresses the dopaminergic } \\
\text { neurodegeneration and movement } \\
\text { disorder }\end{array}$ & {$[232]$} \\
\hline$\overline{\text { DHA }}$ & Schizophrenia & $\begin{array}{l}\text { Neuroprotective properties, especially at } \\
\text { early stages }\end{array}$ & {$[233]$} \\
\hline$\overline{\text { DHA }}$ & $\begin{array}{l}\text { Spinocerebellar } \\
\text { ataxia }\end{array}$ & $\begin{array}{l}\text { an improvement of clinical symptoms } \\
\text { and cerebellar hypometabolism }\end{array}$ & {$[234]$} \\
\hline TG-DHA & $\begin{array}{l}\text { autoimmune } \\
\text { encephalomyelitis }\end{array}$ & Modulate neuroinflammatory processes & {$[235]$} \\
\hline n3-PUFAs & $\begin{array}{l}\text { cognitive } \\
\text { function }\end{array}$ & $\begin{array}{l}\text { enhances expression of soluble epoxide } \\
\text { hydrolase in murine brain }\end{array}$ & {$[236]$} \\
\hline
\end{tabular}


Table 3. Clinical trials omega-3 in the context of neurodegenerative diseases

\begin{tabular}{|c|c|c|c|}
\hline Type of NDs & No of patients & Effect & Reference \\
\hline $\mathrm{AD}$ & 384 & $\begin{array}{l}\text { Brain amyloid pathology may limit } \\
\text { the delivery of DHA to the brain in } \\
\text { AD }\end{array}$ & [2367] \\
\hline $\begin{array}{l}\text { Huntington's } \\
\text { disease }\end{array}$ & 290 & $\begin{array}{l}\text { Ethyl-EPA was not beneficial in } \\
\text { patients with HD during } 6 \text { months of } \\
\text { placebo-controlled evaluation }\end{array}$ & [238] \\
\hline $\mathrm{AD}$ & 174 & $\begin{array}{l}\text { Improved cognitive function in the } \\
\text { omega-3 study }\end{array}$ & [239] \\
\hline $\mathrm{AD}$ & 201 & $\begin{array}{l}\text { The findings in this open-label } \\
\text { extension study warrant further } \\
\text { investigation toward the long-term } \\
\text { safety and efficacy of Souvenaid }\end{array}$ & [240] \\
\hline $\mathrm{AD}$ & 26 & $\begin{array}{l}\text { Souvenaid therapy for the } \\
\text { treatment of behavioral disturbances } \\
\text { and social cognition skills in } \\
\text { behavioral variant of frontotemporal } \\
\text { dementia. }\end{array}$ & [241] \\
\hline Schizophrenia & 79 & $\begin{array}{l}\text { supportive effects on vascular } \\
\text { immune response }\end{array}$ & [242] \\
\hline
\end{tabular}

